\title{
Reflective and Impulsive Determinants of Social Behavior
}

\author{
Fritz Strack and Roland Deutsch \\ Department of Psychology \\ University of Würzburg
}

\begin{abstract}
This article describes a 2-systems model that explains social behavior as a joint function of reflective and impulsive processes. In particular, it is assumed that social behavior is controlled by 2 interacting systems that follow different operating principles. The reflective system generates behavioral decisions that are based on knowledge about facts and values, whereas the impulsive system elicits behavior through associative links and motivational orientations. The proposed model describes how the 2 systems interact at various stages of processing, and how their outputs may determine behavior in a synergistic or antagonistic fashion. It extends previous models by integrating motivational components that allow more precise predictions of behavior. The implications of this reflective-impulsive model are applied to various phenomena from social psychology and beyond. Extending previous dual-process accounts, this model is not limited to specific domains of mental functioning and attempts to integrate cognitive, motivational, and behavioral mechanisms.
\end{abstract}

In the history of attempts to discover the causes of human behavior, the most widespread explanations are based on the assumption that human beings do what they believe is good for them. Thus, they are construed as "rational animals" capable of recognizing the value or utility of their actions.

At the same time, however, it is obvious that human beings do not always act this way; that is, under certain circumstances people behave in ways that do not reflect their values. To account for this phenomenon, to which the Greek philosophers gave the name akrasia (e.g., Mele, 1992), several strategies have been pursued. The first strategy assumes ignorance or lack of knowledge on the part of the actor. Socrates, for example, claimed that if people only knew what is good for them, they would act accordingly. A similar position is held by modern economists who imply that irrational decisions

This article received the 2003 Theoretical Innovation Price of the Society for Personality and Social Psychology (SPSP). This research was supported by grants from the Deutsche Forschungsgemeinschaft (DFG) to Fritz Strack (Str 264/19-1) and from the Deutsch-Israelische Projektkooperation (DIP). The authors are grateful to the members of the Würzburg Social Cognition Group who provided valuable suggestions. Special thanks go to Dolores Albarracin, Axel Bühler, Bertram Gawronski, Arie Kruglanski, Ravit Levy, Thomas Mussweiler, Eliot Smith, Bob Wyer, and five anonymous reviewers for their detailed comments and criticisms. Also, we thank the participants of our seminar on the topic, held in summer and winter 2001 at the University of Würzburg. The project has greatly profited from the lively discussions and the valuable input from our students.

Requests for reprints should be sent to Fritz Strack or Roland Deutsch, Lehrstuhl für Psychologie II, Universität Würzburg, Röntgenring 10, 97070 Würzburg, Germany. E-mail: strack@ psychologie.uni-wuerzburg.de or deutsch@ psychologie.uni-wuerzburg.de reflect a lack of appropriate information (Friedman, 1976). The second strategy postulates more than one set of principles that may control human action. For example, a behavior may occur mindlessly (Langer, Blank, \& Chanowitz, 1978) or automatically; that is, without directing much attention to the utility of an outcome, a person may act the way he or she has acted many times before. Such habitual behaviors were the focus of many psychological theories in which the frequency and recency of previous executions of a given behavior were seen as primary determinants (e.g., Hull, 1943). The third strategy has been to understand human behavior as a function of drives. In particular, basic needs that are biologically rooted, such as hunger, thirst, or reproduction, are seen as major forces. Their strength may override considerations of utility and determine behavior in an immediate fashion.

Although most psychological theories have focused on one of these aspects, some have acknowledged that behaviors may be multiply determined. Most prominently, Freud (e.g., 1933/1949) described human behavior as controlled by a "psychic apparatus" that includes several operating principles: a superego composed of a person's values and norms, an id that operates in accordance with the basic drives a person is endowed with, and an ego that integrates and often reconciles the forces from the superego and the id. Thus, Freudian theory also describes how different processes may interact. In particular, Freud deserves credit for emphasizing the importance of unconscious processes in the determination of behavior. Although Freud's thinking has greatly stimulated psychological theorizing, evidence for the proposed mechanisms was largely anecdotal or based on 
clinical case studies; that is, little evidence has been available to evaluate the postulated processes.

More recently, the conviction that human behavior is guided by more than one underlying process has led to a series of research programs that have resulted in a number of dual-process theories. This converging evidence has been extensively discussed by many authors who contributed to a recent book on dual-process theories in social psychology edited by Chaiken and Trope (1999; for more complex theories of mental processes, see, e.g., Kuhl \& Goschke, 1994). Of course, these theories are not entirely unique but share a considerable number of features. In a systematic comparison, Smith and DeCoster (2000) juxtaposed the nine most prominent models and identified their common and distinctive characteristics.

Most important, all models propose two modes of information processing that are distinguished, according to Smith and DeCoster (2000, p. 111, Table 1), by the following characteristics: rule-based processing "Draws on symbolically represented rules...That are structured by language and logic...And can be learned in just one or a few experiences...Occurs optionally when capacity and motivation are present...And often with conscious awareness of steps of processing;" in contrast, associative processing "Draws on associations... That are structured by similarity and contiguity...And are learned over many experiences... Occurs automatically...And preconsciously, with awareness of the result of processing."

Whereas these characteristics are shared by the major two-process models, Smith and DeCoster (2000) saw the most substantive difference in whether the two types of processes occur simultaneously or in a mutually exclusive fashion. In addition, the existing models are distinct in that they focus on different phenomena and employ different terminology to describe various aspects of the two types of processing. For example, Chaiken, Liberman, and Eagly (1989) as well as Petty and Cacioppo (1986), who are among the proponents of dual-process models, spoke about heuristic/peripheral and systematic/central processing and applied their model to the domain of attitude change. In the spontaneous mode of Fazio's (1986) model of attitude access, well-learned attitudes are assumed to be automatically activated by attitude objects. Only if sufficient motivation and opportunity are present, will deliberative processing determine the evaluation of an object. Devine (1989) focused on stereotyping and assumed either automatic processes or more effortful stereotype suppression. Gilbert (1989) distinguished between correspondent inferences and attributional thinking to explain phenomena of person perception and biases in causal attribution. Martin, Seta, and Crelia (1990) were interested in social judgments and juxtaposed automatic contextual influences and more strategic and effortful attempts at correcting them. Epstein (1991) differenti- ated between experiential and rational processes and applied his theory to general mechanisms of thinking. Finally, Sloman (1996), whose model serves as a conceptual orientation for other dual-process approaches, invoked associative and rule-based processes to account for human reasoning.

Over the years, dual-process models have been refined and updated in various ways. For example, Smith and DeCoster (2000) have integrated new findings from research on memory systems (J. L. McClelland, McNaughton, \& O'Reilly, 1995) to explain how associative and rule-based processing may be rooted in more basic cognitive structures. Lieberman, Gaunt, Gilbert, and Trope (2002) described a cybernetically oriented two-process model while integrating findings from neuroscience. Thus far, however, dual-process models have directed little attention to the behavioral consequences of the mental mechanisms they describe, and they do not provide an alternative to rational models of human behavior. In particular, they are silent on the problem of akrasia. Although there are some accounts that focus primarily on behavior (Bargh, 1990), they do not provide an integration into a comprehensive model of social cognition. This, precisely, is the aim of this article, which attempts to incorporate insights from motivational science (Higgins \& Kruglanski, 2000) into the general dual-process idea.

Although Smith and DeCoster's (2000) survey is certainly not complete (cf. Wilson, Lindsey, \& Schooler, 2000), it is obvious that the processes described in these models focus on judgments and information processing, whereas behavior does not play an integral role. In other words, behavior is implied in these models primarily to the extent that it is preceded by a judgment or a decision. However, behavior is known to occur without such antecedents. For example, judgment-based behaviors may become habitualized through frequent execution and be carried out independent of the implications of the original judgment (Aarts \& Dijksterhuis, 2000; Ouelette \& Wood, 1998). In addition, strong motivational forces may drive a behavior in a direction that is inconsistent with an actor's beliefs and values (Metcalfe \& Mischel, 1999; Strack \& Neumann, 1996). However, such direct influences on behavior have links to mechanisms described in the models summarized by Smith and DeCoster (2000). Therefore, it seemed necessary to integrate behavioral, motivational, and cognitive components into a two-system model of social behavior.

Along with others (Kahneman \& Frederick, 2002), we assume that the processes operate in parallel instead of being consecutively invoked, and we posit that the two systems are concurrently active and compete for control of an overt response. Thus, in contrast to most of the dual-process models previously described, the proposed model is a two-systems model (see also, Gilovich \& Griffin, 2002) of social behavior. 
To enable this model to go beyond explaining the generation of social judgments, we attempt to integrate elements from other research programs that provide links to social behavior. Specifically, the work by Norman and Shallice (1986), Cacioppo, Priester, and Berntson, (1993), as well as Gollwitzer (1999) provided important conceptual elements that added a motivational dimension to the model. In particular, we suggest that behavior is a function of schemata that are jointly controlled by environmental input and superordinate attention (Norman \& Shallice, 1986), and we propose the existence of a motivational orientation that acts as a behavioral catalyst and relates valence to approach and avoidance (Cacioppo et al., 1993). To bridge temporal gaps between a decision and its behavioral implementation, we integrated a mechanism of intending (Gollwitzer, 1999). In addition, we propose that the deprivation of basic needs influences spontaneous evaluation and preactivates behavioral schemata relevant for the satisfaction of the deprived needs.

Taken together, the value of this model is not that it is new in each of its components. Rather, we see its merits in its attempts to integrate elements from existing theories and to describe how they interact at different stages of processing. Most important, we try to tie mental processes to social behavior in a nontrivial way; that is, we do not assume that behavior follows inevitably from a decision and therefore does not deserve attention beyond its cognitive precursors. Instead, we construe social behavior as the result of several determinants that may operate in accord or conflict with each other.

\section{Basic Properties and Functions}

For reasons of clarity, the proposed model is described in 10 theses (see Figure 1 for an overview). As mentioned before, several components are shared by existing dual-process models. The descriptions of those components are somewhat briefer than of those we believe to be unique to this model.

Thesis 1: Basic assumption. Social behavior is the effect of the operation of two distinct systems of information processing: a reflective system and an impulsive system. The systems can be specified by different principles of representation and information processing.

In the reflective system, behavior is elicited as a consequence of a decision process. Specifically, knowledge about the value and the probability of potential consequences is weighed and integrated to reach a preference for one behavioral option. If a decision is made, the reflective system activates appropriate behavioral schemata through a self-terminating mechanism of intending. In contrast, the impulsive system activates behavioral schemata through spreading activation, which may originate from perceptual input or from reflective processes. As described in James' (1890) ideo-motor principle (see also Lotze, 1852), a behavior may be elicited without the person's intention or goal. In addition, the activation of behavioral schemata may be moderated by motivational orientations or deprivation.

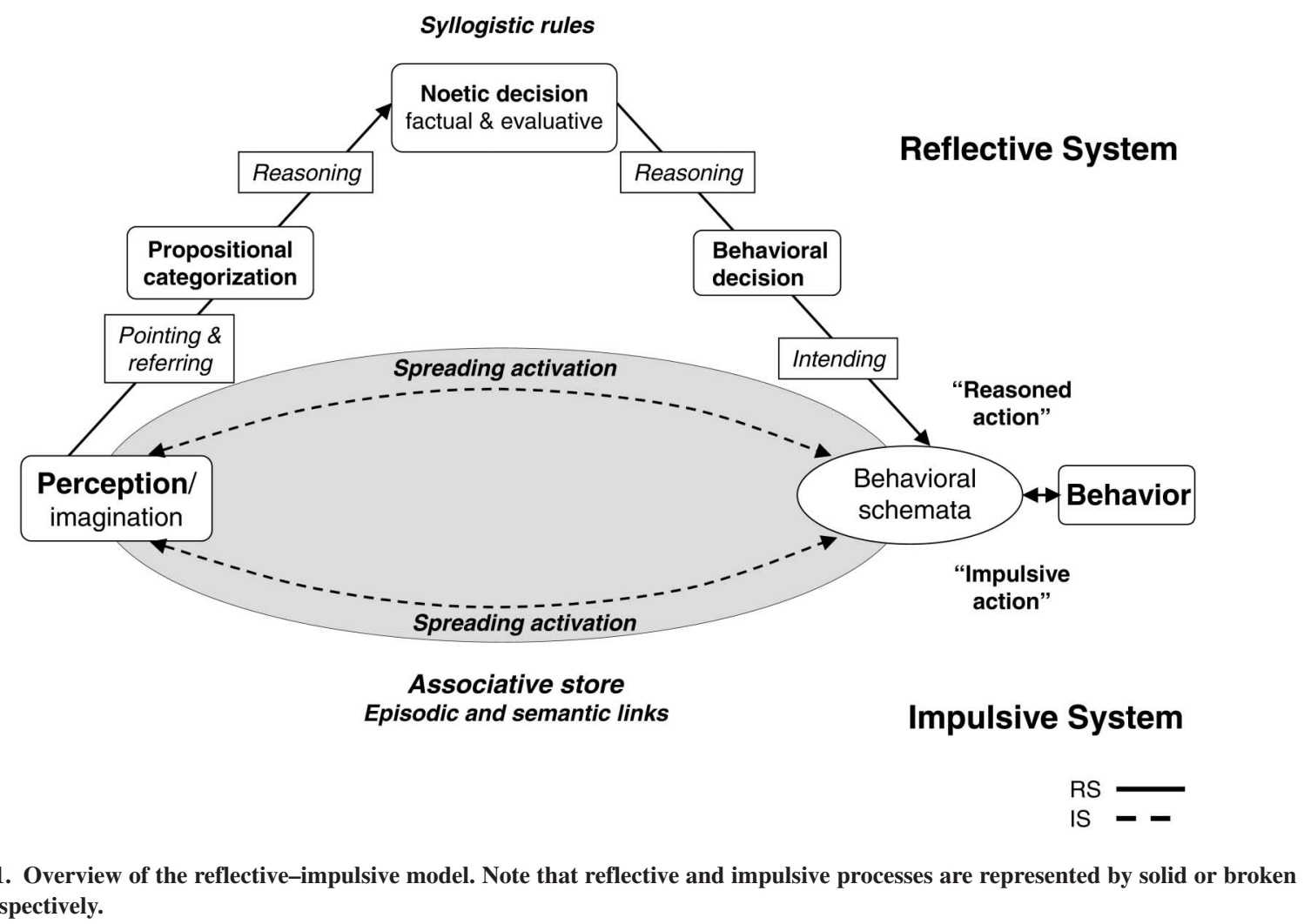

lines, respectively. 
Thesis 2: Parallel operation. Both systems operate in parallel. However, there is an asymmetry such that the impulsive system is always engaged in processing (by itself or parallel to operations of the reflective system) whereas the reflective system may be disengaged.

This model assumes that information entering the perceptual gates will always be processed in the impulsive system. However, the impact of that information depends to a great extent on the preactivation of those structures in the impulsive system in which the information is represented. Depending on its intensity and the attention it receives, a stimulus may also enter the reflective system. In that case, impulsive and reflective processing occurs in parallel, and are assumed to interact at various stages of processing.

Thesis 3: Capacity. The reflective system requires a high amount of cognitive capacity. Therefore, distraction as well as extremely high or low levels of arousal will interfere with its operation. In contrast, the impulsive system requires little cognitive capacity and may control behavior under suboptimal conditions. As a consequence, processes of the reflective system are disturbed more easily than those of the impulsive system.

One of the greatest advantages of the impulsive system is that it is fast, requires no or little cognitive effort, and has a low threshold for processing incoming information, whereas the opposite holds for reflective operations. The reflective-impulsive model shares this assumption with almost every dual-process model, and relevant evidence is reviewed elsewhere (see, e.g., Chaiken \& Trope, 1999; Smith \& DeCoster, 2000). However, we emphasize the role of arousal for a proper functioning reflective system. Resembling the Yerkes-Dodson Law (Yerkes \& Dodson, 1908), we propose that the reflective system operates most efficiently at intermediate levels of arousal. On one hand, high levels of arousal facilitate well-practiced, dominant responses (Hull, 1943; Zajonc, 1965). Recent findings have demonstrated that arousal also affects social judgments and perception, in that it enhances the influence of stereotypic and evaluative associations (e.g., Bodenhausen, 1993; Paulhus \& Lim, 1994). More important, this effect has been recently attributed to a weakening influence of high arousal on controlled or reflective processes (e.g., Baron, 2000; Lambert et al., 2003). On the other hand, very low levels of arousal, as in the state of drowsiness, are associated with poor reflective processing and poor self-control (e.g., Baumeister \& Heatherton, 1996).

\section{Representation, Storage, and Processing of Information}

Thesis 4: Relations between elements. Elements in the two systems are connected by different types of relations. In the reflective system, elements are connected through semantic relations to which a truth value is assigned. In the impulsive system, the relations are associative links between elements and are formed according to the principles of contiguity and similarity.

The world as well as inner states of the organism are represented in different ways in the two systems. In the impulsive system, information is represented in patterns of activation in an associative store. In contrast, the reflective system is capable of forming propositional representations by connecting one or more elements through the instantiation of relational schemata to which a truth value is attached. Of course, representations in both systems are ultimately implemented within a neuronal network; the difference between simple associations and propositional representations therefore refers to the computational level of cognitive modeling (Marr, 1982). ${ }^{1}$

\section{Associative Links and Structures in the impulsive system}

In this model, the impulsive system is conceived of as a simple associative network. In accordance with most other associative-network models (see Smith, 1998), we assume that the links between elements have different strengths that are stable and change only gradually through learning. If an element is activated, activation spreads to other elements in proportion to the strength of the link. The activation of elements in the network can vary rapidly. The accessibility of a content will be increased by the frequency and recency of prior activation. In this way, an element acquires an activation potential (Higgins, 1996) that reduces the amount of additional activation necessary for retrieval or further processing.

In general, links are created or strengthened if stimuli are presented or activated in close temporal or spatial proximity. The resulting links reflect correlations between aspects of the environment and cognitive, affective, or motor reactions, without representing the causes of such multimodal correlations. As a consequence, structures emerge in the impulsive system that bind together frequently co-occurring features and form associative clusters. In essence, we assume that the associative store of the impulsive system works like a simple memory system (see Johnson \& Hirst, 1991), which slowly forms enduring, nonpropositional repre-

${ }^{1}$ Marr (1982) distinguished between the computational, algorithmical, and implementational level of cognitive processes. 
sentations of the typical properties of the environment over many learning trials (see J. L. McClelland et al., 1995; Smith \& DeCoster, 2000). The impulsive system has low flexibility but is fast and needs no attentional resources.

In addition, associative links can be formed through reflective operations. This is possible because every propositional representation in the reflective system activates corresponding contents in the impulsive system. As a result, elements that do not co-occur in reality but are often related to each other in the reflective system will also become associatively linked in the impulsive system (cf. Smith \& DeCoster, 2000). Thus, semantic concepts will emerge in the impulsive system through frequent propositional categorizations. It is important to note that the links in the impulsive system, different from some other network models (e.g., Collins \& Quillian, 1969), are not assumed to have any semantic meaning by themselves. Therefore, the only relation between two or more elements is that of a mutual activation.

For example, if we see an elderly person, perceptual features such as hair color or body posture may activate specific elements in the impulsive system (see Figure 2). Because such elements have previously been paired with other features that are correlated with advanced age, a whole cluster of elderly features will be activated. As a consequence, contents of the elderly stereotype will be more readily accessible and may guide subsequent processing. For example, the concept of slowness may become activated in the impulsive system and reflect our direct or indirect experiences with elderly people.
Although the connections between elements in the impulsive system do not carry a truth value and do not reflect declarative knowledge about elderly people being slow, the associative link between elderly and slow may bias perception and influence behavior if it is activated. Moreover, it is possible that motor programs that have been executed frequently in connection with elderly people in the past may again be activated. Research on the connection between perception and behavior bolsters the idea that semantic concepts can be directly connected to motor programs (e.g., Bargh, Chen, \& Burrows, 1996; Dijksterhuis \& Bargh, 2001). Recent findings on the interplay of gestures and lexical access indicates that this connection is bidirectional (e.g., Krauss, Chen, \& Gottesman, 2000). Associative clusters in the impulsive system can be hierarchically structured and can therefore differ in abstractness. As a consequence, clusters may resemble either concrete perceptual concepts or abstract semantic concepts or schemata.

Processes in the impulsive system may be accompanied by an experiential state of awareness; that is, without necessarily knowing its origin, people may experience a feeling with its distinct phenomenal quality. For example, a person may have a visual perception of lightness or darkness, a pleasant or unpleasant feeling, or the experience of pain or familiarity without knowing the concepts or categories of light, pleasantness, pain, or familiarity. Thus, the impulsive system can be understood as a system of experiential primacy, in which affective and nonaffective feelings are generated quickly and without syllogistic processes of inference (see also Zajonc, 1980).

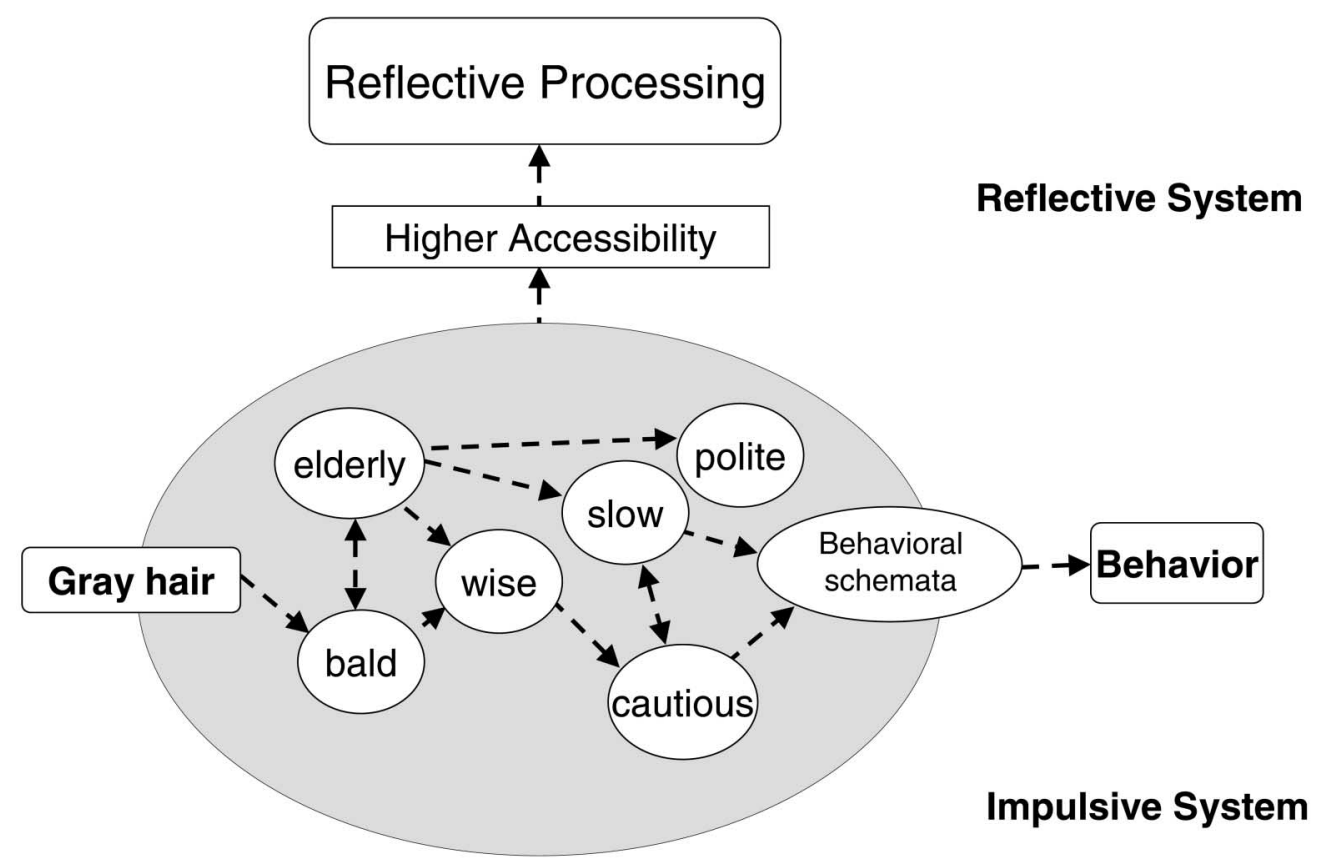

Figure 2. Activation of a hypothetical elderly cluster in the impulsive system. The perception of gray hair leads to a higher accessibility of associated contents and may facilitate associated behavior. 


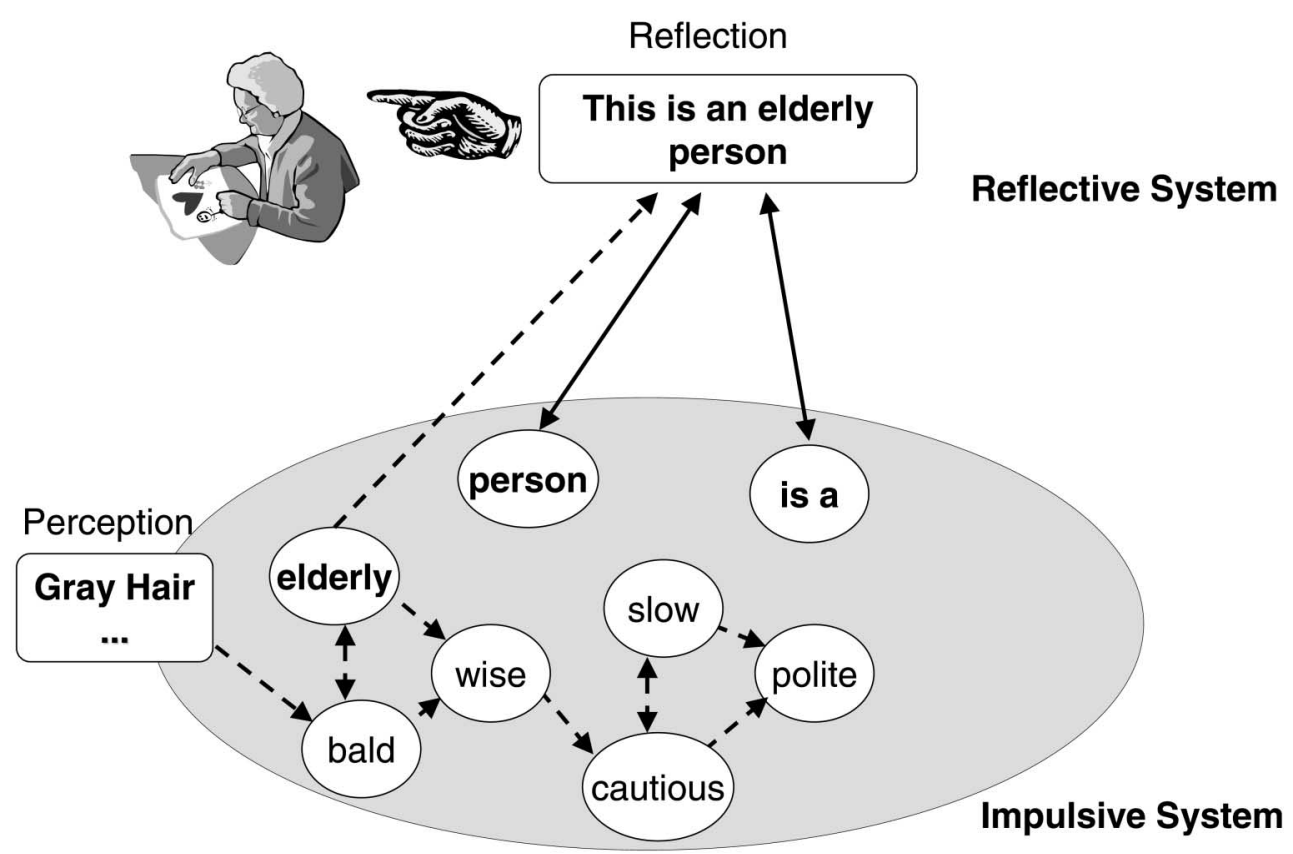

Figure 3. Schematic representation of a propositional categorization. The concepts elderly and person, as well as the relation is $a$, are retrieved from the impulsive system and transformed into a proposition.

\section{The Generation of Knowledge \\ Through Propositional \\ Categorizations and Syllogistic \\ Inferences in the Reflective System}

The impulsive system can be thought of as long-term memory, whereas the reflective system has the properties of a temporary storage in that the amount of information that can be represented at any given time is limited, and the representation will fade if it is not rehearsed (Baddeley, 1986). The reflective system generates declarative knowledge by assigning perceptual input to a semantic category. Unlike simple associative links and structures, knowledge in the reflective system consists of one or more elements to which a relational schema is applied. Most important, a truth value is assigned to that relation. As a consequence, this system represents states of the world or the organism in a propositional format. In this endeavor, the reflective system is driven by the principle of consistency as it strives to avoid or remedy inconsistencies between its elements (Gawronski \& Strack, in press). An important feature of representations in the reflective system is that they can be flexibly generated and changed. Thus, the reflective system can solve a multitude of tasks, such as reasoning, planning, or mental simulation. However, it is slower than the impulsive system and requires attentional resources.

How are such representations generated? We assume that the elements of the proposition - that is, one or more concepts and the relation that is applied to themare retrieved from the impulsive system. The reflective system generates semantic or episodic knowledge by assigning a truth value to the concept and the relation. Take again the perception of an elderly person. The perceivable features have spread activation to the elderly concept in the impulsive system. To generate a propositional categorization, the relational schema of category membership (is a) will be retrieved from the impulsive system and combined with the label elderly and the representation of the perceptual input, in this case the visual representation of the person. Thus, the propositional representation this is an elderly person is generated (for a detailed computational account on how relations and their arguments are bound together to compose propositions, see Hummel \& Holyoak, 2003; see Figure 3).

The number of relations that can be applied to these contents is nearly infinite. Beside simple logical relations, such as is a, is not, or implies, there are also more complex and abstract relations, such as causality. In addition, there are many social relations such as friend, enemy, spouse, or partner. Of course, new relations can develop as a person's knowledge expands.

Once knowledge has been generated, syllogistic ${ }^{2}$ rules are applied to draw inferences that go beyond the information given (Bruner, 1973). For example, a person may wonder how wise an elderly person is. Categorical knowledge about the elderly may be derived from the categorization of a given person as elderly. The quality wise may then be inferred based on this categorization. Note again the fundamental difference to the mere activation of the concept, which facilitates the inference but does not generate knowledge about

${ }^{2}$ The term syllogistic is meant to refer to all types of rules that are used for the transfer of truth from the premises to the conclusion. There are no implications about the validity of such syllogistic inferences. 
elderly people being wise. This becomes particularly apparent in attributional thinking such that the characterization of a particular behavior may spontaneously activate categories that correspond with personality traits (Uleman, 1999). However, these categories may eventually not be used to categorize the person because the context implies alternative causes of the same behavior (e.g., Trope, 1986).

Operations of the reflective system are accompanied by a noetic state of awareness, which consists of knowledge that something is or is not the case. ${ }^{3} \mathrm{~A}$ noetic state of awareness may be accompanied by an experiential state of awareness, which consists of a particular feeling. For example, the process of trying to answer an almanac question may be accompanied by a feeling of knowing (Koriat, 1993).

\section{The Role of Accessibility}

The assignment of a relation to elements is strongly influenced by the accessibility of a category (Higgins, Rholes, \& Jones, 1977). For example, the belief that a particular person is slow depends on the ease with which the concept slow comes to mind, which, in turn, depends on the associative strength between the perceptual input and the concept, that is, on the recency and the frequency of their joint activation. Of course, more elaborate inferential strategies that are the basis of further transformational processing may also be applied to generate propositional knowledge (i.e., causal attribution or hypothesis testing).

Because the reflective system uses contents from the impulsive system, reflective operations will alter the accessibility of these contents. As a consequence, subsequent operations in the reflective system will be influenced by their predecessors. An example of this influence comes from recent work on the psychological mechanisms underlying the so-called anchoring bias (Tversky \& Kahneman, 1974), which refers to the assimilation of an absolute judgment toward the standard of a preceding comparative judgment. In a series of studies, Mussweiler and Strack (see Strack \& Mussweiler, 1997; for a review, see Mussweiler \& Strack, 1999) demonstrated that this bias results from the use of information that has been selectively activated during the comparative judgment task preceding the absolute judgment.

\section{Contents of Representations and Noetic Decisions}

The content of propositional representations can take many different forms. It may be objects from the outside world but also experiences that come "from

\footnotetext{
${ }^{3}$ The term noetic was introduced to experimental psychology by Tulving (1985), who differentiated between anoetic, noetic, and autonoetic kinds of consciousness.
}

within” (Bless \& Forgas, 2000). In particular, feelings of different qualities may enter into the reflective system if they are propositionally categorized and contextually qualified (e.g., Schwarz \& Clore, 1983). A good example of how feelings that emerge from impulsive processing can enter reflective processes and even determine choice comes from a study by Bechara, Damasio, Tranel, and Damasio (1997). In this experiment, participants had to choose cards from four decks, two of which offered high gains at the risk of an occasional high loss, while the other decks offered lower gains but with a smaller risk of a loss. Overall, the less risky deck led to a higher payoff.

When participants were asked to choose from the four decks, they reported having a feeling which of the decks were good and bad long before they could name the payoff matrix of the game. This impulsive reaction to the playing situation was also mirrored by changes in skin conductance before participants chose a risky card, and participants frequently based their choice on these feelings. Another informational basis for the generation of knowledge about others and about the self is observed behavior. As described by attribution and self-perception theory (Bem, 1967; Kelley, 1967), people may infer internal states (such as attitudes) from their own behavior or that of others, and from the context in which it occurs.

It is important to note that noetic decisions can be made not only about what is the case but also about what is good or bad, because the syllogistic rules also apply to evaluative judgments, such as attitudes (see Schwarz \& Bohner, 2001); that is, a person may infer that something is good or bad based on premises with evaluative content. To arrive at an evaluative decision, it is neither necessary nor sufficient that congruent affect is elicited or that the person has an affective experience. This also relates to the distinction between instant utility and the utility judgments that concern the past or the future. In particular, Kahneman and collaborators (for a review see Kahneman, 1999) showed that evaluations of past situations may drastically differ from what was actually experienced. In retrospect, individuals seem to rely primarily on the frequency and the extremity of negative or positive peaks in experienced utility, thereby neglecting the duration of hedonic experience (but see Schreiber \& Kahneman, 2000). Judged or remembered utility refers to a noetic judgment, whereas experienced utility accrues from an impulsive reaction to hedonically relevant situations.

To be sure, such experiences may accompany the reflective processing of evaluative (and factual) information and facilitate or inhibit reflective processes. For example, a recent set of experiments (Greene, Sommerville, Nystrom, Darley, \& Cohen, 2001) found that incongruent affect may interfere with evaluative judgments. Specifically, research participants had to judge whether it was justifiable to sacrifice one human 
life to save five. The scenarios were constructed such that more or less negative affect was elicited by considering the sacrifice. This was checked by fMRI recordings of the brain during decision making. It was found that under the high negative affect condition, more time was required to make incompatible decisions (i.e., justifying the sacrifice) than compatible decisions (i.e., not justifying the sacrifice). When no or less negative affect was elicited by the decision task, the response time did not differ as a function of the outcome of the decision. In congruence with a recent model of moral judgment (Haidt, 2001), this finding suggests that people may use their affect as a basis of such a judgment, and that the affect may be in conflict with considerations based solely on value and expectancy.

Finally, reflective operations may instigate or moderate affect. Although in some cases merely perceiving a specific situation is sufficient to activate affect in the impulsive system (Le Doux, 1995; Zajonc, 1980), in other circumstances considerable reasoning is necessary to infer the affective relevance of a situation (Lazarus, 1984). In this case, the reflective-impulsive model assumes that reflection activates affect-specific contents in the impulsive system that then lead to the experiential state. However, knowing that something is good (or bad) does not necessarily imply a positive (or negative) feeling. In fact, the insight that a specific action might be good can be accompanied by a bad feeling, for example the upcoming appointment with one's dentist. On the other hand, positive feelings toward an action may be accompanied by a negative evaluation of what one may be about to do (i.e., temptation).

\section{Representing What Is Not the Case: Negations and the Future}

As is outlined later, the assumption of different representational principles in the reflective and impulsive system has various implications for current topics in social and cognitive psychology. However, it also affects capabilities that are fundamental to our thinking and acting. Specifically, the two representational principles contribute to a deeper understanding of how we comprehend that something is not the case (i.e., how we negate), and how we think about the future.

Negation. Negating - that is, reversing the truth value of a proposition - is not only a widespread tool of thinking (e.g., Wason \& Jones, 1963) but also a convenient means of everyday communication (e.g., MacDonald \& Just, 1989). Because negations are propositional statements (Horn, 1989; Mall, 1975), boundary conditions for their successful computation can be derived from the reflective-impulsive model. Most important, Thesis 4 implies that the cognitive procedure of negating can only be executed in the reflective system. Consequently, only if there is sufficient process- ing time, intention, and cognitive capacity to extract the meaning of a negation (e.g., no money) will the reflective system be engaged and the task successfully completed. However, if one of these conditions is not met, the negation may be processed only in the impulsive system. In this case, the negated concept (e.g., money) and the negating qualifier (e.g., no or not) will become activated in the impulsive system, however they will not be applied to the concept. Consequently, the immediate effects of processing this information will be identical to those of processing the same information in an affirmed format or even without a qualifier attached to it.

We are certainly not the first to propose that processing negations is a resource dependent process. A great number of studies demonstrates that negations slow down cognition (Wason, 1959) and are prone to error (Fiedler, Armbruster, Nickel, Walther, \& Asbeck, 1996; Ross, Lepper, \& Hubbard, 1975; Wegner, Coulton, \& Wenzlaff, 1985). Gilbert's (1991) sequential model of negating describes how negations may be represented in memory. In particular, the model suggests that all information in memory is true as long as it is not "tagged" as false. This tagging process is assumed to consume cognitive resources. Empirical evidence consistent with this assumption comes from a wide array of research. For instance, Gilbert, Krull, and Malone (1990) asked participants to learn a fictitious vocabulary by reading translations (e.g., "a waihas is a fish"). In addition, participants were immediately told that the translation was either true or false; in some trials, participants were distracted as this information was conveyed. In those cases, false translations were later more often remembered as being true than true translations were remembered as being false. In other words: If participants were distracted, negated information had similar effects as affirmed information. This phenomenon was replicated in other experiments using a wide range of materials (e.g., Gilbert, Tafarodi, \& Malone, 1993).

Because these studies typically assessed later judgments or recollections, the results may be due to either the actual encoding of negations or the later recall of the information. In a series of experiments, Deutsch, Gawronski, and Strack (2003) used priming measures to assess more directly the actual processing of negations. In these experiments, the effects of evaluative priming using affirmed versus negated words as primes were compared to evaluative judgments of the same stimuli, which were elicited under conditions that are favorable for reflective processing. The results demonstrated that under the priming conditions, effects of affirmed and negated stimuli were identical, whereas the evaluative judgments were strongly affected by the negations. This implies that the inefficiency of a negation cannot be reduced to characteristics of memory.

In addition, a study by Wegner, Ansfield, and Pilloff (1998) showed that this dissociation applies not only to 
cognitive tasks but also to the self-regulation of behavior. In that experiment, participants were asked to hold a pendulum and try to prevent it from swinging. Not surprising, they were better at holding the pendulum still if they were not distracted by a secondary task. In a second condition, however, the researchers specifically asked participants to prevent the pendulum from swinging along the $\mathrm{x}$ axis that was marked on a piece of paper. Most surprising, in the distraction condition the pendulum swung more along the $\mathrm{x}$ axis when participants were explicitly instructed to prevent this from happening compared to when they were given no such instructions. If it is true that a depletion of cognitive resources increases the likelihood that the impulsive system will control behavior, the instruction not to perform a certain behavior may have strengthened the link to a behavioral schema that produces the undesired behavior.

Although under specific conditions, the reflective-impulsive model generates similar predictions as Gilbert's (1991) sequential model of negation, the two models are not identical. Whereas Gilbert's model focuses on the representation of negations in memory, the reflective-impulsive model accounts for memory and retrieval, as well as for the use of retrieved negations in judgmental tasks. Specifically, we assume that during the encoding of a negation, a link between the negated concept and the negating qualifier will be established in the impulsive system. Moreover, we propose that the establishment of such a link in memory and its use in judgments are two distinct processes. In contrast, it is implied in Gilbert's (1991) model that when a false tag has been added to a piece of information, it will be always correctly recognized as being false. From the reflective-impulsive model it follows that for participants who are low on cognitive resources when they use a piece of information that had been associated with a negating qualifier the effects of negated information will be similar to those of affirmed information, despite the fact that the link to the negation is available in memory. In addition, the frequent rehearsal of a negation may strongly increase the accessibility of the negated concept, as well as the negation itself. As a consequence, a feeling of familiarity may arise when thinking of the negated concept; at the same time, the label false may pop into one's mind. This may cause ambiguity, as the experiential cue directly opposes what is implied by the retrieved qualifier. Finally, the reflective-impulsive model predicts that links between concepts and negating qualifiers may develop either through reflective elaboration or through frequent coactivation, which is independent of reflection. Note again that a false tag is not sufficient for the use of a negation in the course of social judgments. These predictions from the reflective-impulsive model have yet to be tested.

In sum, the reflective-impulsive model can account for known phenomena in the realm of negations and generate new predictions that are open to empirical testing. The main advantage of the reflective-impulsive model is that these predictions follow directly from its general principles.

Representing the future. The second important consequence relates to the ability to represent the future. Because it is more independent from immediate perceptual input, only the reflective system can explicitly generate a time perspective. Specifically, events that are expected to occur in the future may be categorized as such. This provides an important means of understanding courses of action and developments over time. More important perhaps, it allows for the development of strategies to pursue goals that are remote in time. While the impulsive system is driven by immediate perceptual input, the reflective system is able to abstract from the immediate input and bridge temporal gaps. This allows individuals to resist immediate rewards and strive for more valuable future outcomes.

Empirical evidence supporting this notion comes from a recent series of experiments by Deutsch and Strack (2002). In particular, they established learning conditions under which people were led to emit impulsive reactions that were opposed to their reflective knowledge. Participants where asked to open red and blue "doors to a photo gallery" on the computer screen. Depending on the color of the door, their actions had different consequences at different points in time. In one condition, a particular color was immediately followed by a photo of an extremely negative valence from Lang's collection (International Affective Picture System, IAPS; Center for the Study of Emotion and Attention, 1995), which was presented for $800 \mathrm{~ms}$. Four sec later, an extremely positive picture appeared for another $4 \mathrm{sec}$. In the other condition, the valence of the two photos was reversed.

Asked which photo gallery they would prefer, people more frequently chose the contingency consisting of the immediate but short exposure of the unpleasant and the delayed but much longer exposure of the pleasant photo. However, the delayed utility should not determine participants' reaction if a response has to be emitted under conditions that prevent the reflective system from operating. This was the case when participants were instructed to open the doors under the conditions of the stop paradigm (Logan, Schachar, \& Tannock, 1997). This procedure has been used as a behavioral measure of impulse strength, which is inferred from the ease with which a response can be deliberately inhibited. As predicted by the reflective-impulsive model, impulse strength was determined by the valence of the stimulus that was immediately associated with the color of the door; that is, if the short but immediate valence was positive, participants were less able to inhibit the elicited response than if it was negative. In other words, the stimuli acquired "hot" features (see Metcalfe \& Mischel, 1999) 
through learning, which influenced behavioral impulses and conflicted with the "cool" knowledge about reward contingencies that vary over time.

\section{Behavioral Control}

A crucial component of the reflective-impulsive model is its assumption that the reflective and impulsive systems elicit behavior through different processes. However, the execution of impulsively or reflectively elicited behaviors is carried out by behavioral schemata that are part of the impulsive system. We elaborate this assumption by first discussing the development and operation of behavioral schemata in the impulsive system. Then, we describe how behavioral schemata can be activated through impulsive and reflective processes.

\section{Final Common Pathway to Behavior}

Thesis 5: Execution of behavior. There exists a final common pathway to overt behavior in the impulsive system that may be activated by input from the reflective and the impulsive system. This pathway consists of behavioral schemata of varying abstractness. If the schema is activated above a certain threshold, the behavior will be executed.

In this model, elements in the impulsive system consist of sensory, conceptual, affective, and motor representations that can be interconnected (see section on representation and processing). Typically, the following three elements constitute a behavioral sequence: the situational condition, the behavior proper, and the consequences of the behavior. The model assumes that similar learning principles hold for all types of representations. Thus, associative clusters will emerge in the impulsive system that bind together frequently co-occurring motor representations with their conditions and their consequences. These sensory-motor clusters are called behavioral schemata, and similar to other contents of the impulsive system, they are subject to spreading activation and differ in their activation potential. In addition, if one part of a behavioral schema is activated, the activation will spread to the remaining elements of the cluster. Behavioral schemata and their links to other contents in the impulsive system can be understood as habits (see Aarts \& Dijksterhuis, 2000; Ouelette \& Wood, 1998).

In concordance with Norman and Shallice (1986), we assume that impulsive and reflective processes can lead to the activation of behavioral schemata, however the two systems differ in how they activate a behavioral schema. This is described in the following paragraph. An important assumption is that more than one behavioral schemata can receive activation at a time. However, activation must exceed a given threshold to result in overt behavior.
Conflicts may arise if behavioral schemata are activated that are incompatible and inhibit one another. For example, through mechanisms of the impulsive system, the sight of food may activate an eating schema while the reflective system is executing a decision to stop eating. The resolution of the conflict depends on the strength of the activation for each schema. If the schemata are activated by the different systems, the conditions that influence their operation determine which schema will prevail. For example, the reflective system will be more likely to control the behavior if the necessary cognitive capacity is available. Conversely, the impulsive system will be more likely to have the upper hand under a strong deprivation of basic needs or under a motivational orientation that facilitates the execution of the behavior. These possibilities will be discussed in a later section.

\section{Precursors of Behavior}

Thesis 6: Precursors of behavior. The systems use different operations to elicit behavior. In the reflective system, behavior is the consequence of a decision that is guided by the assessment of a future state in terms of its value and the probability of attaining it through this behavior. In the impulsive system, a behavior is elicited through the spread of activation to behavioral schemata.

Impulsive precursors of behavior. As behavioral schemata are part of the impulsive system, they can be easily activated by impulsive processes. In particular, perceptual input may activate elements in the impulsive system that are associated with behavioral schemata or even a part of them. For example, seeing a cup will activate a drinking schema. In addition, imaginative input as well as reflectively activated content of the impulsive system may elicit associated behavioral schemata. Thus, thinking about a cup is assumed to activate a drinking schema.

Note that the impulsive precursors of behavior do not imply knowledge about valence and expectancy. Although not in the form of simple reflexes, perception is linked to behavior in a direct fashion, as described by the ideo-motor principle (James, 1890). James assumed that "every representation of a movement awakens in some degree the actual movement which is its object" (p. 396). This is consistent with the assumption that in the impulsive system, conceptual content and behavioral schemata are bidirectionally linked. This holds for either conceptual representations of antecedents or consequences of a behavior, as well as for the behavior itself. Research supporting the idea of a link between conceptual and motor contents is reviewed elsewhere (Dijksterhuis \& Bargh, 2001) 
Reflective precursors. In the reflective system, behavior is the result of reasoning that leads to a noetic decision about the feasibility and desirability of a particular action (cf. Ajzen, 1991; Bandura, 1977). If the execution of the behavior is deemed to be feasible and its outcome positive, a behavioral decision will relate the self to the behavioral outcome.

Although this reflective procedure seems to guarantee a reasoned action as its behavioral consequence, the previous thesis points to influences from the impulsive system that are outside the deliberator's attention. In particular, the differential accessibility of information about behavioral options or about relevant aspects of the alternatives may direct reflective processing; that is, although a procedure may be rational with respect to the normative model, it is influenced by contents whose accessibility is determined by factors unrelated to rational considerations (e.g., Gregory, Cialdini, \& Carpenter, 1982).

However, a behavioral decision may not immediately elicit a goal-directed behavior. Instead, activation may spread to several behavioral schemata and concepts in the impulsive system. There may be at least two reasons why the appropriate behavior may not be executed immediately. First, other behavioral schemata that are incompatible with the behavioral decision may be activated. This issue will be addressed in the following. Second, the behavioral decision may refer to a later point in time. This issue is addressed in the section on intending.

\section{Synergistic and Antagonistic Interplay of Decisions and Impulses}

Thus far, we have described how impulsive and reflective processes may jointly activate behavioral schema that control overt behavior. The effect on behavior, however, depends on the compatibility of the two forces. Specifically, if the reflective system and the impulsive system contribute to an activation of the same schema, the behavior is facilitated. Moreover, the cognitive capacity required to control the execution will be decreased and the execution of the behavior may be accompanied by a feeling of fluency, which has a positive hedonic quality (Winkielman \& Cacioppo, 2001). Together with the positive evaluation of the outcome, the cooperation of the two systems has enormous motivational implications.

However, the two systems may also compete if they activate incompatible schemata or if the reflective system inhibits the execution of a behavior that is impulsively activated. Such antagonistic activation may be accompanied by a feeling of conflict and temptation. For example, a person who is on a diet may be tempted to eat a second dessert (see Figure 4); that is, the sight of the dessert impulsively activates behavioral schemata that are directed toward consumption. At the same time, the reflective system has generated a behavioral decision to refrain from eating it. To win the contest, the reflective system can apply knowledge about the mechanisms of the impulsive system. Most effectively, it may divert attention from the tempting stimulus.

Finally, it is important to note that although both systems may contribute to the execution of behavior, the impulsive system can assume primary control if the operating conditions (see Thesis 3 ) for the reflective system are not fulfilled. As a result, behavior is less likely to be determined by the assessed valence and the probability of future consequences than by the immediate associations and the resulting hedonic quality.

\section{Intending}

Thesis 7: Intending. In the reflective system, a behavioral decision is linked to behavioral schemata by the process of intending. Intending monitors the impulsive system for information that enables the behavioral implementation of the decision. The mechanism of intending is terminated if the behavior is executed or if the goal of the preceding behavioral decision is already fulfilled.

An important factor we must take into consideration is that frequently an action cannot be executed at the time the behavioral decision is made. In fact, the execution of many decisions depends on specific conditions that are not yet fulfilled. Thus, there may be a gap between a behavioral decision and an action. If the execution of a reflectively chosen behavior depends on the activation of behavioral schemata, constant activation would be necessary to bridge possible temporal gaps. However, such a permanent rehearsal of behavioral programs would absorb a great amount of cognitive capacity and increase the risk that the behavior is executed before the appropriate conditions are fulfilled. This, however, does not seem to be adaptive and may even be detrimental with respect to the proper pursuit of the goal.

Therefore, we suggest a process of intending as it has been discussed in modern theories of human motivation (e.g., Gollwitzer, 1999). We assume that the temporal gap between a behavioral decision and the execution of an instrumental behavior is bridged by a process that automatically reactivates the behavioral decision and thus activates behavioral schemata that are appropriate in the situation. Moreover, we assume that the process of intending is self-terminating; that is, when the goal of the decision has been reached, the process is turned off.

We predict that intending also plays a role if a goal is blocked. Because of the hierarchical organization of goals, people may check the instrumentality of the obstructed goal vis-à-vis a superordinate objective and choose a different means to the same end. Although the appropriate evidence is still lacking, we expect that other than through trial and error, the circumvention of 


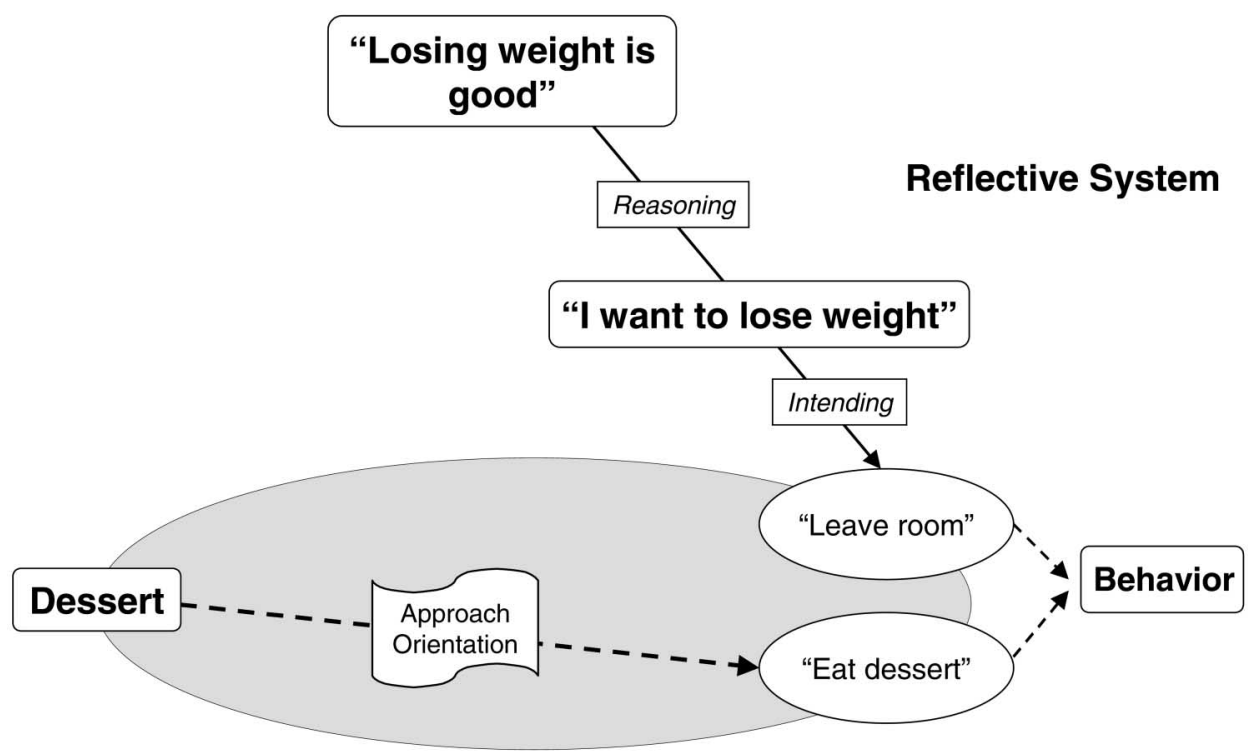

\section{Impulsive System}

Figure 4. Impulsive and reflective activation of competing behavioral schemata. While the perception of a dessert directly activates an approach tendency, the noetic decision to lose weight leads to the behavioral decision to go for a walk instead of eating the dessert.

obstacles requires the reflective system to establish alternative means-ends relationships and initiate a new operation of intending.

\section{Motivation}

So far, we have described the reflective system as a highly flexible system when it comes to action, whereas the impulsive system appears to be relatively rigid. Specifically, changing evaluations in the reflective system may result in new decisions and their concomitant behavioral consequences. In contrast, the impulsive system seems to be driven by the perceptual input as it is connected to behavioral schemata. Changes of these links are assumed to develop slowly following the law of effect, the law of readiness, and the law of practice (Thorndike, 1911).

However, there are some ways in which the impulsive system can also react more flexibly, taking external and internal conditions into account. For external conditions, we propose that the impulsive system can alternate between two distinct motivational orientations that guide the processing of information and the activation of behavior. For internal conditions, we propose a specific way by which homoeostatic dysregulations may influence impulsive processing. Both motivational aspects are outlined in more detail in the following sections.

\section{Motivational Orientation}

Thesis 8: Motivational orientation: The impulsive system can be oriented toward approach and avoidance. This motivational orientation may be elicited by

- the processing of positive or negative information,

- the perception of approach or avoidance,

- the experience of positive or negative affect,

- the execution of approach or avoidance behaviors.

In the impulsive system, processing of information and the execution of behavior are mediated by two motivational orientations (Cacioppo et al., 1993). In accordance with other theorists (e.g., Gray, 1982; Lang, 1995; Sutton \& Davidson, 1997), we assume that these functional orientations serve to prepare the organism for two fundamental types of reactions toward the environment: approach and avoidance. Approach orientation is a preparedness to decrease the distance between the person and an aspect of the environment. This includes physical locomotion, instrumental action, consumption, or the imagination thereof. Avoidance orientation can be conceptualized as a preparedness to increase the distance between the person and the environment. This can be achieved by either moving away from a target (flight) or by causing the target to be removed (fight). The specific type of response within both motivational orientations is determined by other influences.

Because evidence for the existence of approach and avoidance systems is extensively reviewed elsewhere (Gray, 1982; Lang, 1995), we focus here on the relationship between affect, behavior, and information processing within the two motivational orientations. The following thesis is grounded in the idea that processing of positive information and the experience of positive af- 
fect are most important for the regulation of approach behavior, whereas the processing of negative information and the experience of negative effect are most important for the regulation of avoidance behavior.

Thesis 9: Compatibility. The processing of information, the experience of affect, and the execution of behavior are facilitated if they are compatible with the prevailing motivational orientation.

The following propositions can be derived directly from Thesis 9: If the impulsive system is oriented toward approach, it facilitates the processing of positive information, the experience of positive affect, and the execution of approach behavior. In an avoidance mode, it facilitates the processing of negative information, the experience of negative affect, and the execution of avoidance behavior. Moreover, Thesis 9 implies the principle of bidirectionality, that is, a reverse causal influence (cf. Neumann, Förster, \& Strack, 2003). Specifically, a motivational orientation may be elicited by the valence of the processed information, the valence of affect, or the orientation of a behavior (approach vs. avoidance).

In the reflective system, a behavior may become the basis for inferences about its underlying attitude (Bem, 1967). This, however, requires that the behavior is propositionally categorized. That is to say, only if the behavior is related to a category (e.g., forgetful) can it enter into syllogistic inferences. In contrast, processing in the impulsive system and the principle of bidirectionality allow a behavior to influence processing without being propositionally categorized; that is, people are influenced by what they are doing even if the meaning of an action is not recognized.

In the following discussion, we first review evidence backing the idea that behavior may have a direct effect on the processing of information that occurs in the impulsive system and is therefore not mediated by syllogistic inferences. At the same time, this evidence serves as support for Thesis 9, which refers to compatibility as a basic principle of the impulsive system. Then we focus on the reversed direction of influence and review studies that illustrate the impact of evaluative information on behavior. The principles of motivational orientation are represented in Figure 5.

\section{The Compatibility Principle I: The \\ Direct Impact of Behavior on Mental Processes}

Facial feedback. Self-perception theory (Bem, 1967) is among several applications that have been harnessed to explain a phenomenon in the domain of emotional expression. Specifically, it has long been argued (e.g., Darwin, 1872/1965) that facial (and other bodily) expressions serve to not only communicate feelings to others and thereby regulate social exchanges but also to increase or diminish the intensity of an affective experience. Applied to the face, Darwin's facial-feedback hypothesis has been studied from a self-perception perspective. Most prominently, Laird (e.g., 1974) found that experimental participants who had been asked to adopt a smiling expression gave a more positive judgment about themselves (e.g., their own well-being) and about affective stimuli (e.g., cartoons) that had been presented to them. According to self-perception theory, participants inferred their affective state from their facial expression. Such an inference, however, requires that the behavior be interpreted as the expression of a particular affective state; that is, a person can only infer that she must be happy (or amused) if she knows that she is smiling.

From the perspective of the reflective-impulsive model, this is not the only way in which an overt behavior may influence mental processes. The inferences described by self-perception theory operate according to the principles of the reflective system; the impulsive system, in contrast, allows for different mechanisms. Specifically, it follows from Thesis 9 (compatibility) that behavior may directly influence information pro-

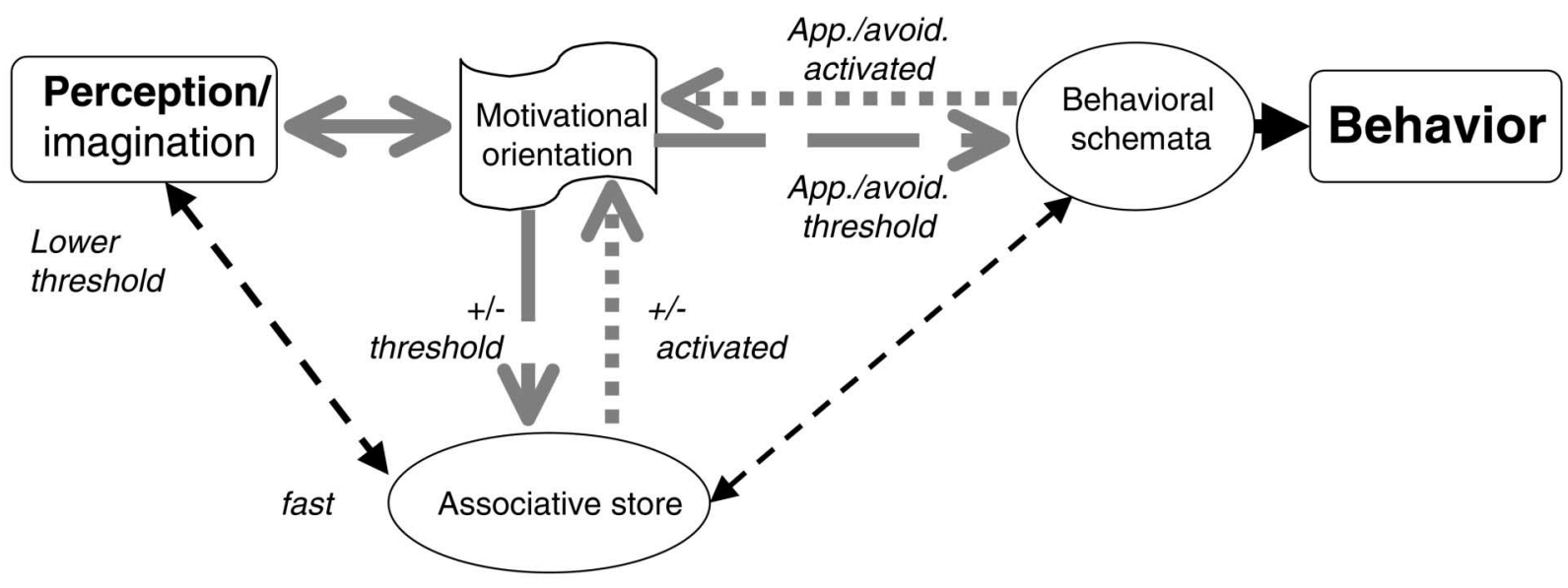

Figure 5. Principles of motivational orientation. 
cessing. In detail, the behavioral schemata that activate an emotional facial expression are assumed to be linked with evaluatively compatible thought contents and perhaps with affective experiences, and this facilitates the processing of the affective information.

This process may be mediated either through the hedonic quality of the emotion or through the approach-versus-avoidance function of the behavior. In the case of the induced smile, we assume that the impulsive system facilitates the processing of positive information. As a consequence, cartoons will be rated as funnier and people will feel more amused.

However, to demonstrate that a facial expression may influence an emotional experience even if individuals do not draw an inference from the behavior, it was necessary to prevent people from recognizing the emotional meaning of their facial action. This was achieved by embedding the contraction of the facial muscle (in this case, the zygomaticus) in a task unrelated to an emotional expression. Specifically, under the pretext of investigating how people who must do so write or paint with their mouth, Strack, Martin, and Stepper (1988) asked experimental participants to hold a pen either between their teeth or between their puckered lips while rating several cartoons interspersed among other tasks. Thus, the teeth-holding position activated the zygomaticus muscle, which is used in smiling; the cover story prevented participants from interpreting their facial action as "a smile." Nevertheless, people assigned to this experimental condition reported feeling more amused and rated the cartoons as funnier than people who held the pen with their puckered lips.

These findings (see also, Bodenhausen, Kramer, \& Suesser, 1994; Erber, 1991; Martin, Harlow, \& Strack, 1992; Zajonc, Murphy, \& Inglehart, 1989) show that the effect of facial feedback does not depend on inferences from the perceived emotional meaning of a facial expression. Rather, facial feedback may also affect mental processes in a more direct fashion, which can be explained easily and parsimoniously by the mechanisms that the reflective-impulsive model ascribes to the impulsive system.

Postural feedback. Extending the same logic to another medium of expressing emotions, Stepper and Strack (1993) induced experimental participants to adopt an upright or slumped posture under the pretext of studying different working conditions. Based on previous studies (Riskind, 1984), Stepper and Strack expected that people would experience the emotion of pride more intensely when adopting an upright body position. Again, those earlier studies did not rule out that people drew an inference from the quality of their posture about the quality of their emotional state. In the Stepper and Strack study, however, the posture was disguised as an ergonomic investigation. Still, partici- pants who were induced to believe they had scored above average in a preceding task and were asked to adopt an upright body posture while they received this feedback reported feeling prouder than participants who received the same information while adopting a slumped posture. This result corroborates and extends the previous facial-feedback findings (Strack et al., 1988). It shows, in a different expressive dimension, that the impact of posture on mental processes does not hinge on inferences that are based on the perceived meaning of the bodily action.

Head movements. Although these studies clearly demonstrate the phenomenon, they are not explicit about the exact mechanisms that afford such a direct influence of a behavior on mental processes. Subsequent studies were more informative. In particular, a series of experiments in which we (Förster \& Strack, 1996) explored the effect of head movements on the recognition of words sheds light on some underlying mechanisms. Participants were asked to nod or shake their head while reading positive and negative words. To disguise the communicational meaning of the head movements as an act of agreement or disagreement, we had participants "test headphones to be used while dancing" (Wells \& Petty, 1980). Specifically, participants were required to perform either horizontal or vertical head movements while the words were played on a cassette recorder.

As expected, we found that the head movements affected performance in a surprise recognition task. In particular, participants who had been induced to nod were better at recognizing positive words, while participants who had been induced to shake their head were better at recognizing negative words. Moreover, this proved not to be a response bias that affects the threshold for words of a particular valence. Rather, the data showed that when the head movement was compatible with the valence of the word, people were better at discriminating whether the word had been presented. This suggests that the behavior influenced the processing of the words at the time of the encoding.

This encoding hypothesis was tested more directly in a second experiment, using a dual-task paradigm. More specifically, while participants were explicitly instructed to learn the words while nodding or shaking their head, they were also required to perform a manual dexterity task. If head movement facilitates (or inhibits) the encoding of information, more (or less) cognitive capacity will be left to perform the secondary task. As a consequence, we predicted a better manual dexterity performance if the learning of positive words was accompanied by nodding, and the learning of negative words by shaking one's head. Conversely, the outcome of the dexterity task should be poorer if positive words are learned while shaking one's head, and negative words while nodding. The results supported these predictions. Moreover, the in- 
clusion of neutral words showed that facilitation and inhibition occurred as a function of valence-motor compatibility or incompatibility.

These findings provide evidence for motor influences on mental processing when the behavior has no immediate evaluative implications. However, these implications are mediated by a motivational subsystem of which the behavior is a part. In most cultures, nodding is a nonverbal signal for agreement and shaking one's head for disagreement; these head movements are therefore linked to an orientation toward approach or avoidance that influences the way behavior is impulsively regulated. Tuning the impulsive system to an orientation of approach facilitates the processing of positive information and inhibits the processing of negative information. Conversely, tuning the system toward avoidance facilitates the processing of negative information and inhibits the processing of positive information. Thus, head movements and the valence of words are either compatible or incompatible and facilitate or inhibit the processing of information.

Approach and avoidance through isometric muscle contractions. Similar effects were obtained for a motor action that was previously found to influence positive and negative affect. In particular, Cacioppo and his collaborators (e.g., Cacioppo et al., 1993) discovered that pressing the palm of one's hand from the bottom against the surface of a table, thereby activating the flexor muscle of the arm, led to positive attitudinal judgments, while pressing from the top against a table platform, thereby activating the extensor muscle, led to negative attitudinal judgments. Cacioppo et al. (1993) argued that through previous associations, flexor and extensor actions elicit a motivational orientation of approach versus avoidance.

The reflective-impulsive model integrates and extends Cacioppo et al.'s (1993) notion of a motivational orientation that can be activated by any behavior compatible with approach or avoidance. It should therefore be possible to apply the described influence of head movements to reproduction memory (Förster \& Strack, 1996) using the flexor-extensor paradigm. This was in fact achieved by Förster and Strack (1997) for the reproduction of famous names; that is, contracting the flexor muscle facilitated the recall of positively connotated names, whereas contracting the extensor muscle improved the recall of negatively connotated names.

The postulated principle of compatibility and bidirectionality found additional support in a study by Neumann and Strack (2000), who used a different dependent variable. In particular, participants who were presented words on a computer screen had to decide if these words were positive or negative in valence. As predicted by the reflective-impulsive model, we found that positive words were categorized more rapidly when participants had been induced to flex their arm, whereas negative words were categorized more rapidly when participants had to contract the extensor muscle.

Finally, Seibt and Neumann (2002) applied the flexor/tensor procedure to the assessment of cartoons and found that participants reported feeling more amused if the flexor muscle was contracted than if the tensor or no muscle was activated. Moreover, Seibt and Neumann found that reported social anxiety (elicited by the expectation of having to speak in front of a large audience) was increased if participants had been induced to contract the tensor muscle.

Direct activation of a motivational orientation. In the reported studies, the link between a behavior and the processing of evaluative information was assumed to be strengthened through the prevailing motivational orientation. To repeat, the impulsive system may be oriented toward approach or avoidance (cf. also Lang, 1995), and this orientation may be triggered by the valence of the processed information, by the experience of compatible affect, and by the perception of movements that imply approach or avoidance. An activated motivational orientation results in the lowering of thresholds for the processing of compatible information (i.e., positive information for the approach and negative information for the avoidance orientation), and for the elicitation of compatible behaviors that stand in a functional relationship with the orientation.

One way of activating a motivational orientation is to put people in a situation in which the distance between the person and an object appears to be increasing or decreasing; that is, if the distance is decreasing, the impulsive system should be oriented toward approach; if the distance is increasing, the impulsive system should be oriented toward avoidance. As a result, the processing of compatible information should be facilitated.

In a very direct test of this notion, Neumann and Strack (2000) gave participants an evaluative decision task in which the valence of positive and negative words presented on a computer screen had to be categorized. More important, these words were presented in the center of circles that were either increasing or decreasing in size. As documented in a manipulation check, the changing size of the circles created the appearance that the words were moving either toward the person or away from the person, although the actual size of the letters remained constant. As predicted by the reflective-impulsive model, this apparent change in the distance between the target and the person influenced the evaluative decision such that the valence of positive words was categorized faster if the word appeared to be moving toward the viewer, whereas the valence of negative words was categorized faster if the words appeared to be moving away.

To verify that this finding does not depend on the evaluative nature of the task, we used the same paradigm for a lexical decision task in which the stimulus 
material consisted of not only positive and negative words but also neutral words and nonwords. Participants were asked to decide whether a letter string on the screen was a word. Again, the response latencies were as predicted: Lexical decisions for positive words were faster if the letter strings appeared to be moving toward the person, while lexical decisions for negative words were faster if the letter strings appeared to be moving away. This suggests that the predicted facilitation effect is not a function of the evaluative nature of the task but depends solely on the valence of the stimuli (see also, Chen \& Bargh, 1999).

\section{The Compatibility Principle II: The Impact of Evaluative Information on the Execution of Behavior}

On several occasions, we have emphasized bidirectionality as a signature characteristic of the impulsive system. This implies that a behavior may activate a motivational orientation, which then lowers the threshold for the processing of compatible information. However this also implies, conversely, that the valence of information may exert a facilitating influence on compatible behaviors that is mediated by the motivational orientation. Concretely, it implies that the behaviors that served as independent variables in the experiments described in the preceding paragraphs should also operate as dependent variables. The available evidence supports this implication.

Facial action. As described in a previous section, unobtrusively manipulated facial expressions were found to influence evaluative judgments (Strack et al., 1988). Conversely, we expected that facial actions would be facilitated if compatible information is processed. This prediction was confirmed in a still unpublished set of experiments by Neumann and Hess (2001), in which participants had to respond by contracting their facial muscles. In particular, under the pretext of studying whether responses to psychological tasks emitted by body parts that are closer to the brain differed from responses produced by more remote body parts (such as the hand), participants had to contract the corrugator or the zygomaticus muscle. Surface electrodes recorded the EMG activity of both muscles while participants assessed the valence of words presented on a computer screen. As predicted, the positivity of words was indicated faster with the help of the zygomaticus (smiling) muscle, while the negativity of words was assessed faster if participants were using the corrugator (frowning) muscle. As in previous studies, it was important to find out whether the effect depended on the evaluative nature of the task, or whether the evaluative nature of the stimulus influenced the processing even for tasks with no evaluative implications (see Neumann \& Strack, 2000).
To that end, Neumann and Hess (2001) conducted a second experiment in which participants had to merely indicate when a stimulus appeared on a computer screen. The stimuli were positive or negative words, and the reactions had to be provided by either contracting the corrugator or the zygomaticus. Again, the compatibility between the valence of the stimuli and the nature of the motor action determined the response latencies. Participants indicated the appearance of positive words faster when using the zygomaticus muscle, and the appearance of negative words faster when using the corrugator muscle.

These findings provide clear evidence for the bidirectionality postulated by the reflective-impulsive model. In particular, it was shown that facial action provides not only feedback (Laird, 1974) by influencing the processing of evaluative information but also that its execution is controlled by the valence of information.

Approach and avoidance through isotonic movements. In previous studies that were based on a procedure by Cacioppo and associates (e.g., Cacioppo et al., 1993), we were able to show that the processing of positive versus negative information was facilitated depending on whether the flexor or the extensor muscle was contracted (Förster \& Strack, 1997, 1998; Neumann \& Strack, 2000). This effect was expected because the contractions are associated with movements of approach and avoidance. The postulate of bidirectionality predicts the opposite causal direction. In particular, movements that are directed toward the person should be facilitated if positive information is processed, whereas movements away from the person should be easier if the information is negative.

First evidence for this influence came from a study by Solarz (1960), who presented cards with words that were either positive or negative. Depending on the words, participants had to either push these cards away from themselves (avoidance) or pull them toward themselves (approach). Solarz found that participants were faster if the valence of the word and the movement were compatible; that is, faster reactions were observed if positive words had to be pulled toward the person and negative words had to be pushed away.

This finding was replicated by Chen and Bargh (1999), who had participants evaluate words on a computer screen as good or bad by either pushing or pulling a lever. In line with Solarz' (1960) findings, lower response latencies were obtained if the valence of positive words had to be indicated by pulling the lever or the valence of negative words by pushing the lever. In a second study, Chen and Bargh (1999) showed that this compatibility effect did not depend on the evaluative nature of the task. Rather, it was also obtained if the task was simply to indicate whether a word (that was either positive or negative) appeared on the screen. 
Head movements. Vertical or horizontal movements of one's head influence the encoding of negative or positive information (Förster \& Strack, 1996). The reverse, however, is also the case. Wells and Petty (1980) found that people nodded their head more often if they agreed with the content of an attitudinal messages they heard through headphones. Similarly, Förster and Strack (1996) observed that when participants had to nod while encoding the words, positive words increased the rate of nodding. Conversely, if people had to shake their head, negative words increased the rate of shaking.

Affect as a determinant of motivational orientation. The distinction between two motivational orientations is closely related to a model proposed by Lang and his associates (for a review, see Lang, Bradley, \& Cuthbert, 1990), who postulated appetitive and aversive motivational systems that facilitate behavioral responses. Based on biological and neuropsychological evidence, these researchers assume that "associations, representations, and action programs that are linked to the engaged motivational system have a higher probability of success" (Lang, 1995, p. 377). Moreover, these motivational systems are activated by an organism's emotional or affective state. An extensive program of research with animals and humans found that startle responses were increased when negative affect had been elicited. This was particularly the case for the emotion of fear. At the same time, the startle response was found to be inhibited if the organism was in the state of positive affect.

These findings support the reflective-impulsive model in its assumption of a motivational orientation that links mental and behavioral processes. At the same time, the dynamics of the impulsive system and the role of the motivational orientation go beyond the mechanisms identified by Lang and his associates (e.g., Lang, 1995). For example, the reflective-impulsive model treats behavior as a dependent and an independent variable. As previously described, a particular behavior may elicit a motivational orientation, which may then facilitate the processing of compatible information. In the reflective-impulsive model, the motivational orientation functions by selectively lowering the threshold for the processing of evaluatively compatible information and for the execution of functionally compatible behaviors. At the same time, the motivational systems theory provides important links to underlying biological substrates, particularly the role of the amygdala.

\section{Homoeostatic Dysregulation}

Thesis 10: Homoeostatic Dysregulation. Deprivation of basic needs will lead to an activation of those behavioral schemata that in the past frequently led to satisfaction of those needs.

Motivational orientations only moderate the execution of behavior and the processing of information based on valence. Although this is true for a wide range of behaviors, some situations may call for a more specific disposition to act. In particular, if basic needs are not satisfied, specific behaviors are necessary to remedy this state of deficiency. To account for the influence of basic needs within the reflective-impulsive model, we invoke a mechanism resembling the notions proposed in early drive theory (Hull, 1943). In particular, we propose that whenever a state of deprivation is successfully abolished, behaviors and situational circumstances that led to satisfying the need become strongly linked to the experience of this deprivation (cf. Dickinson \& Balleine, 2002). Consequently, if the same need is deprived again, the behavioral schemata and conceptual contents that were previously related to the satisfaction will again be activated and produce a behavioral preparedness and a perceptual readiness for the processing of relevant information in the environment (Bruner, 1957). For example, the deprivation of food will facilitate behavioral schemata of food intake and spread activation to conceptual representations of food. As a result, stimuli that are related to food should be recognized more easily under conditions of food deprivation.

This was found in an experiment conducted by Wispe and Drambarean (1953), who asked participants to recognize words that were presented very briefly on the computer screen. Some of their participants had not eaten for 10 or 24 hours, whereas others had had a snack just prior to the experiment. Moreover, the words were either food related or not. As expected, hungry participants were faster at detecting food-related words than neutral words. However, no such difference was observed in participants who were not hungry. Similar results were recently obtained by Aarts, Dijksterhuis, and De Vries (2001) for thirst and drinking-related words. Support for our notion that people's attention toward stimuli that are capable of reducing the deprivation is increased by the behavioral schemata is provided by a study by Lavy and van den Hout (1993). Based on fasting participants' ratings of food valence and urge to eat, Lavy and van den Hout concluded that attentional bias in a Stroop task was more likely to come from an increased urge to act than from deprived people's emotional experience. The increased accessibility of need-relevant concepts may also guide the interpretation of ambiguous stimuli. For example, D. C. McClelland and Atkinson (1948) demonstrated that hungry participants were more likely than satiated participants to identify ambiguous stimuli as food-related objects.

Homoeostatic dysregulations may also modulate evaluative responses. As Lewin (1935) noted, the valence of an object "usually derives from the fact that 
the object is a means to the satisfaction of a need" ( $p$. 78). Existing evidence shows that need-related objects are experienced to be more positive under deprivation (e.g., Drobes et al., 2001; Lavy \& van den Hout, 1993). Moreover, it has been demonstrated that need-irrelevant objects are devaluated (Brendl, Markman, \& Messner, 2003). That such shifts of valence occur impulsively was recently demonstrated by Seibt, Häfner, and Deutsch (2003) who found in two experiments that evaluative associations related to food as well as spontaneous orientations toward approach versus avoidance depended on food deprivation.

It is important to note that the link between deprivation and the facilitation of behavioral schemata and the activation of conceptual contents is believed to develop only for needs that are immediately experienced. Other dysregulations (such as that of blood pressure) are not experienced. Thus, the described behavioral and conceptual mechanisms will not be elicited.

\section{Affect and Emotion}

Affect and emotion are understood as products of the reflective and the impulsive system. Following Russell's (2003) theory of emotion, our model implies that the impulsive system generates a simply structured state of core affect that, by reflective processes, can be transformed in more elaborate feelings and emotions. In particular, we assume that a person's core affect is a state that can be experienced on the dimensions of hedonic quality and arousal. Thus, a person may feel good or feel bad in a way that is accompanied by high or low activation. Because the origin of this state is not part of the experience, situationally and chronically accessible contents may be reflectively assigned as causes.

As a consequence, a noetic awareness emerges along with the experienced affect. For example, people may feel good (or bad) about themselves. At the same time, they may engage in behaviors that are directed by the valence of the affective quality and fueled by the state of activation. Based on emotional schemata, the particular configuration of experience and knowledge may then be categorized as a particular emotion. Then, a person may, for example, feel proud about a particular achievement (e.g., Neumann, Seibt, \& Strack, 2001) or disappointed at a friend's betrayal.

Thus, the reflective-impulsive model does not claim that specific emotions produce specific behaviors. Rather, it maintains that behavioral schemata are impulsively influenced by habit strength, motivational orientation and homeostatic dysregulation. In addition, reflective considerations may enter into the equation. For example, we do not assume that fighting is a necessary behavioral consequence of anger whereas fleeing is a necessary result of fear. Instead, and in agreement with Russell's (2003) model, we propose that the evaluative quality of the information orients the system toward in- creasing the distance (i.e., avoidance). Whether this is accomplished by moving away from the target (i.e., flight) or by causing the target to be removed (i.e., fight) depends on determinants in the situation and in the person (e.g., Keltner, Grunfeld, \& Anderson, 2003), or the level of activation. The experienced emotions of fear or anger are the categories that are used to represent the entire emotional episode in the reflective system.

From this conceptualization it follows that affect may influence behavior in at least two ways. First, core affect possesses a motivational orientation toward approach and avoidance that facilitates concomitant behaviors. Second, affective experiences may be propositionally categorized and become the basis of syllogistic inferences that may lead to noetic and behavioral decisions. Both possibilities are discussed in this article. For a more detailed integration of affect and emotion into dual-system notions, see Smith and Neumann (in press).

\section{Automaticity}

During the past 15 years, automaticity has become an increasingly important topic in social psychology (e.g., Bargh, 1990; Bargh \& Ferguson, 2000). Even such complex social-cognitive processes as goal activation (e.g., Bargh \& Barndollar, 1996), trait inferences (e.g., Gilbert, 1989), or the imitation of social behavior (e.g., Dijksterhuis, Bargh, \& Miedema, 2000) have been shown to operate outside consciousness, without intention, to be hard to control as well as highly efficient (cf. Bargh, 1996). It is a widely held assumption that automaticity of cognitive procedures is achieved through frequent execution (e.g., Anderson, 1981). As Bargh (1997) put it: "Any skill, be it perceptual, motor, or cognitive, requires less and less conscious attention the more frequently and consistently it is engaged" (p. 28).

How can automaticity be understood from the vantage point of the reflective-impulsive model? Of course, it is the impulsive system to which the central criteria of automaticity (see Bargh, 1997) apply. Particularly its independence from intention and its high efficiency follow from its architecture as an associative network. In contrast, the reflective system is assumed to depend heavily on cognitive resources and to generate intentions through behavioral decisions. However, according to the reflective-impulsive model, the quality of the impulsive mechanisms differs from that of reflective processes, which is why a direct transposition of reflective procedures to the impulsive system is not possible.

This raises the question of how controlled processes can become more automatic? The reflective-impulsive model implies several mechanisms that play a role (cf. Smith, 1994; Smith, Branscombe, \& Borman, 1988). The first and most simple mechanism is that contents from the associative store of the impulsive system are used and thus activated during reflective processing. If 
information is transformed through a syllogistic procedure (e.g., to infer the valence of a negated word), the input to the procedure (e.g., the negated word) as well as its output (e.g., the resultant valence) will be activated in the impulsive system. If this is repeated frequently, the joint activation of input and output will establish an associative link between the two contents. Thus, the results of previous syllogistic procedures are stored in memory and eventually can be retrieved in an automatic fashion (cf. Logan, 1988).

This memory-based mechanism predicts only a narrow transfer of automatic responses to new instances or situations. In particular, only the reaction to those or similar (cf. Palmeri, 1997) instances that were practiced can be elicited in an automatic fashion. However, the reflective-impulsive model can also account for more general effects of practice (see also, Anderson, 1993). First, the operational principles of the reflective-impulsive model imply that the frequent execution of reflective procedures makes the representation of these procedures more accessible for further use. Second, representations of procedures may become associated with situations in which they were frequently carried out. Finally, syllogistic procedures may become associated with other procedures if they are frequently carried out in temporal proximity. Consequently, complex syllogistic operations may become more efficient through practice, because the more specific procedures they consist of can be quickly retrieved from memory.

These assumptions set limits for automatic processing under specifiable circumstances. An example is the well-practiced cognitive operation of negating. Evidence (Deutsch et al., 2003) suggests that through the frequent execution of this operation, semantic links will be created that facilitate further processing. For example, the term no way has acquired its own meaning whereas the term no hay needs further reflective processing to be understood, independent of the frequency with which the former negation is used. It is therefore the particular content that profits from frequent practice, but not the generalized application of the rule. In this model, the frequent execution of reflective mechanisms may form associations and allows the impulsive system to "take over." However, this does not mean that the reflective procedure of negating will be performed automatically; rather, it will be substituted by a different mechanism that fulfills the criteria of automaticity.

Although the idea that the same psychological procedure can be transposed from one operational mode to another has a venerable history in psychology and goes back to Helmholtz's (1867) notion of unconscious inferences, we second Lieberman et al. (2002) in that the idea of automatic processes as merely faster and quieter versions of controlled processes "is theoretically parsimonious, intuitively compelling, and wrong" (p. 205).

\section{Application to Phenomena in Social Psychology}

In the remainder of this article, we discuss the implications of the reflective-impulsive model (see Figure 6 for the full model) for various aspects of social psychology and illuminate its potential for explaining different phenomena of social behavior. Special emphasis is given to predictions where this model will go beyond or differ from existing dual-process models.

\section{Implicitness and Explicitness in Attitudes, Prejudice, and Stereotyping}

In the past decade, research in social psychology has increasingly focused on so-called implicit phenomena (e.g., Farnham, Greenwald, \& Banaji, 1999). In particular, central concepts such as stereotypes, prejudice, attitudes, or goals were assumed to operate not only as contents of consciousness but also outside of conscious awareness (e.g., Banaji, 2001; Blair, 2001). To study such implicit phenomena, new methods of research have been developed (e.g., Maass, Castelli, \& Arcuri, 2000), such as the implicit association test (Greenwald, McGhee, \& Schwartz, 1998), evaluative priming (Fazio, Sanbonmatsu, Powell, \& Kardes, 1986), or affective variants of the Stroop and Simon task (e.g., De Houwer, Crombez, \& Baeyens, 2001). These measures have in common that they do not rely on conscious evaluations of the attitude object itself, thereby circumventing correctional processes because of social desirability or other reasons. Instead, they tap into mechanisms that are automatically instigated by the attitude object.

There is no doubt that the reflective-impulsive model bears a family resemblance to explicit-implicit models in that both notions hold that different mechanisms may mediate between valence and behavior. However, there are several issues on which the reflective-impulsive model takes a divergent position. First, we suggest that the two systems operate in parallel and interact with one another. In contrast, most explicit-implicit models assume a sequential mode of operation (see Smith \& DeCoster, 2000). Second, the partition of the reflective-impulsive model into two systems is not based on the presence or absence of conscious awareness (e.g., Greenwald \& Banaji, 1995). We refrain from using the phenomenal experience that may accompany mental processes as a distinctive criterion because we do not know precisely how consciousness arises from psychological or neural processes. In particular, consciousness is often seen as an epiphenomenon rather than a causal force or even an integral part of cognition (Libet, Gleason, Wright, \& Pearl, 1983; Wegner, 2002). Moreover, categorizing a process as conscious or unconscious provides little information about its computational nature. Therefore, the reflective-impulsive model does not invoke the ex- 


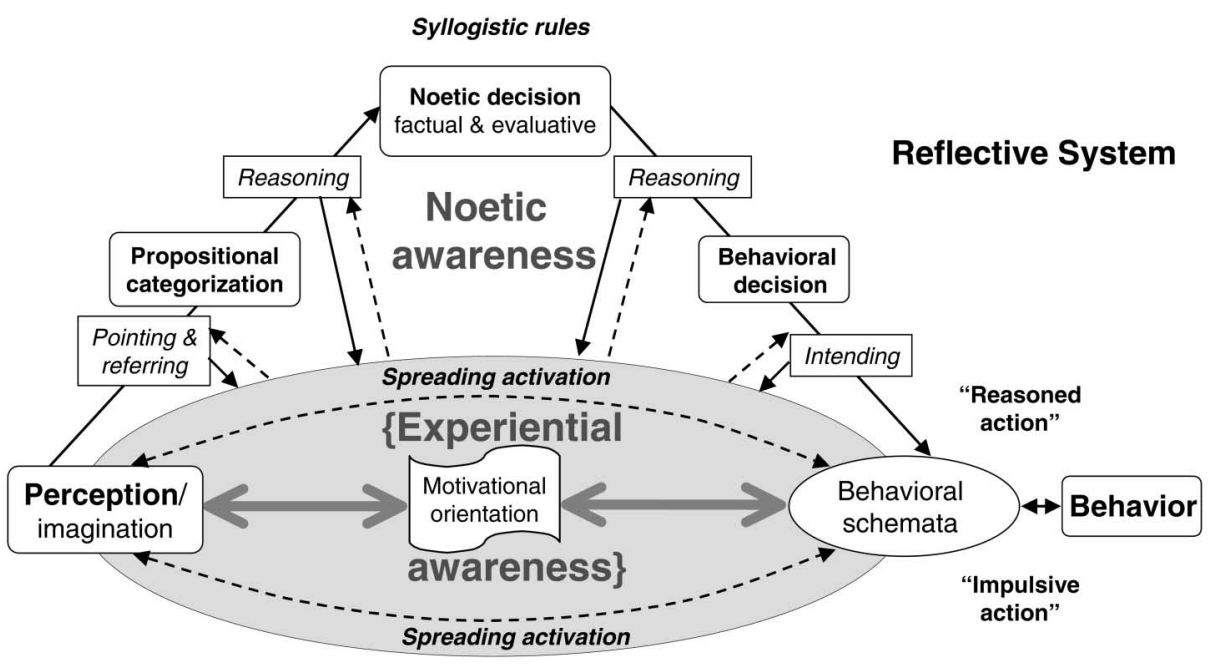

Associative store

Episodic and semantic links

Impulsive System

RS -
IS -

Figure 6. Overview of the complete reflective-impulsive model.

istence of implicit attitudes, implicit stereotypes, implicit goals, or implicit self-esteem.

Some theorists in the field of implicit social cognition have begun to elaborate on more unique features of implicit phenomena. For instance, Wilson et al. (2000) advanced the thesis that implicit attitudes may change more slowly than explicit ones and tend to influence expressive and automatic behaviors. Greenwald et al. (2002) specified implicit associative mechanisms that incorporate principles of cognitive balance. We would like to go one step further and propose to ground the implicit-explicit distinction primarily on operational characteristics. In line with other dual-process models (e.g., Smith \& DeCoster, 2000), we locate implicit processes in the impulsive system, whereas explicit processes are thought to take place in the reflective system. Specifically, we prefer to use the terms explicit versus implicit for psychological processes but not for mental contents. As a consequence, an attitude is defined as a belief following from an evaluative decision that follows from reflection about what is good or bad. At the same time, we talk about evaluative associations to describe links between concepts and evaluative responses in the impulsive system. In a similar vein, stereotypic associations are distinguished from stereotypic beliefs (Devine, 1989).

This conceptualization affects the interpretation of implicit measures. Despite their popularity, the psychological status of what they assess is still unclear (for a review, see Fazio \& Olson, 2003). Some theorists argue that implicit measures identify implicit attitudes or implicit stereotypes (e.g., Wilson et al., 2000); others prefer to view the measure itself as implicit, but not the attitude (or whatever other concept; Fazio \& Olson, 2003). From the perspective of the reflective-impulsive model, explicit and implicit measures are defined by the cognitive operations that they capture. In this sense, explicit measures tap into people's knowledge or beliefs, implicit measures tap into their associative structures.

Beyond redefining the implicit versus explicit dichotomy, the reflective-impulsive model may help to understand how behaviors may be influenced by explicit and implicit mechanisms. Although it has been proposed that the implicit and explicit phenomena may take different routes to behavior (e.g., Dovidio, Kawakami, Johnson, Johnson, \& Howard, 1997; Wilson et al., 2000), most models are relatively mute on the cognitive or motivational structures underlying such influences. The reflective-impulsive model can account for such influences through its inherent interconnections between conceptual and behavioral representations as well as through its motivational orientations.

\section{Automatic Attitude Activation}

Many studies (see Fazio, 2001) have demonstrated that attitudes may be activated very quickly, efficiently, unintentionally, or even unconsciously on the perception of the attitude object. In his influential motivation and opportunity as determinants model (MODE model), Fazio (1990) specified the circumstances under which attitudes may automatically influence behavior. In particular, Fazio assumed that only strongly associated attitudes will exert automatic influences. The main process through which attitudes may influ- 
ence behavior spontaneously is by influencing the perception of the situation. If motivation and cognitive resources are high, however, more deliberate considerations and effortful search in memory may prevail and determine the perception of the situation and finally the behavior.

Although the mechanisms of the reflective-impulsive model are consistent with the tenet that motivation and opportunity (for thorough processing) are preconditions for reflective choice, the model proposes a somewhat different mechanism for nondeliberative processing. Both models assume that objects can be associated with a positive or negative valence. The MODE model suggests that the activation of such positive and negative associations may tune the perception of the situation, which then influences behavior in a spontaneous fashion. Although the reflective-impulsive model includes this mechanism as a possibility, it also affords an alternative option that does not require the operation of the reflective system. Specifically, the reflective-impulsive model proposes that a behavior may be influenced by its facilitation through a motivational orientation that is activated by the valence of the processed contents (see Thesis 9). Finally, the impulsive system provides for the possibility that perception is directly linked to behavioral schemata, allowing for an even more direct path to behavior than the MODE model (see Thesis 5).

Thus, from the perspective of the reflective-impulsive model, the behavioral component of an attitude has a reflective and an impulsive meaning: reflective in that it refers to a behavioral decision that is derived from an evaluation, and impulsive in that it refers to action tendencies that are directly associated with the evaluative features of the attitude object.

\section{Intuitive and Heuristic Judgments}

As mentioned earlier, theorizing in social psychology has been enriched by dual-process models that distinguish between rule-based and associative processing (Smith \& DeCoster, 2000). At the same time, it has been recognized that judgments may be generated in ways that differ in the ease with which they can be performed. In particular, it has been argued that judges may use mental shortcuts to save time and effort. Most prominent, Tversky and Kahneman (1974) identified a set of judgmental heuristics that serve this purpose. Some dual-process theorists (e.g., Eagly \& Chaiken, 1993) have combined the two research programs and proposed that heuristic and nonheuristic judgments are generated by qualitatively distinct processes (for an alternative view, see Kruglanski \& Thompson, 1999; Strack, 1999). First, there is a systematic mode in which judgments are formed following rational or logical principles of the rule-based type of processing. Second, there is an intuitive or heuristic mode in which judgments are generated in ways that are based on various simplified associative procedures that afford decisions under suboptimal conditions.

At first glance, the reflective-impulsive model may seem to mirror this distinction. This, however, is not the case, because there are no reflective versus impulsive ways to social judgments that people can choose as alternatives. Rather, we assume that judgments and decisions are exclusively made by the reflective system, whereas the impulsive system operates in parallel (see Thesis 3). How then can the reflective-impulsive model account for intuitive or heuristic judgments?

The answer rests on a more detailed analysis of what we mean by judgments that are not generated in a systematic fashion. In general, there seems to be agreement that they consist of shortcuts to circumvent effortful and time-consuming systematic processing. From the perspective of our model, there are three types of shortcuts driven by noetic, experiential, or behavioral processes.

Noetic shortcuts are conceived as simplifying inferences based on characteristics of the target. One example is the belief that a long, persuasive message is more valid than a short message (Eagly \& Chaiken, 1993). Thus, the general principle length implies strength is used as a premise in an inference (see Kruglanski \& Thompson, 1999) that allows a person to make a decision without tediously scrutinizing each argument. In a related fashion, the rule of similarity implies category membership may simplify propositional categorizations that would otherwise require complex computations using base-rate probabilities (see Tversky \& Kahneman, 1982).

At the same time, there are experiential shortcuts, which are conceived of as simplifying inferences based on subjective experiences. For example, the mental effort that is experienced while trying to generate a judgment may become the basis for an inference about the target. The probability of an event's occurrence (Tversky \& Kahneman, 1973) and the fame of a person (Jacoby, Kelley, Brown, \& Jasechko, 1989; see also Strack \& Neumann, 2000) seem to be determined by the experienced mental effort. Similarly, affective experiences (such as current mood) may become the basis for inferences about one's own global well-being (Schwarz \& Clore, 1983) or for judgments about consumer goods (Wänke, Bohner, \& Jurkowitsch, 1997).

Noetic and experiential components are combined in a third shortcut that immediately follows from a mechanism described by the reflective-impulsive model: A judgment may be based on a behavioral tendency or a motivational orientation that is produced by the impulsive system. Extending the logic of self-perception theory (Bem, 1967), the noetic and experiential representation of one's behavioral tendencies may enter the reflective system before they are actually carried out. Thus, a person noting that he or she is driven to approach 
a given target may translate this experience into knowledge and use it for inferences about the target.

According to the model we present, the impulsive system plays a passive role in heuristic and intuitive judgments. In particular, its operation may provide an experiential awareness and the associative contents to which mental shortcuts are applied. However, the application of these simplifying rules of reasoning takes place in the reflective system. This is indicated particularly by the fact that judges may correct for a lack of representativeness in the noetic or experiential basis of the judgment. The correctional mechanism in situations where affect is used as information has been repeatedly demonstrated and discussed by Schwarz and Clore (e.g., 1996; for a more general perspective, see Strack, 1992; Strack \& Hannover, 1996).

Thus, although it may seem tempting to connect nonsystematic judgments to specialized intuitive or heuristic processes, the explanation provided by the reflective-impulsive model is quite different. In particular, the model suggests that although judgments and decisions are made in the reflective system, it is important to understand its interactions with the impulsive system. This is particularly obvious in the case of experiential shortcuts where one must ask under what conditions and at what points in the judgmental sequence subjective experience may enter into the reflective system.

\section{Regulatory Focus}

One of the most influential theories in recent motivational science is regulatory focus theory (RFT; Higgins, 1997), which predicts how strategies of approach and avoidance result from positive and negative events that are experiences or expected. This topic has been under research for a long time, and RFT is in line with the conventional view or hedonic principle (e.g., Gray, 1982; Lang, 1995) in that considering the presence of a positive valence as an outcome (gain) elicits a type of approach orientation that is described as promotion focus, whereas considering the presence of a negative valence as an outcome (loss) elicits an avoidance orientation or a prevention focus. However, RFT goes beyond the hedonic principle when it comes to motivational effects of considering nongains and nonlosses as outcomes. According to RFT, deliberating about nongains as possible outcomes of one's action is connected to a promotion focus and should therefore elicit an approach-type orientation, although its overall valence is negative. Similarly, deliberating about nonlosses as possible outcomes is assumed to instigate a prevention focus and therefore avoidance-type behaviors, despite its overall valence is positive.

Applying the reflective-impulsive model to this topic leads to a more differentiated prediction. In particular, different motivational orientations are assumed to depend on whether operations are carried out in the impulsive or in the reflective system. As was outlined before, we believe that the impulsive system adheres to the hedonic principle (i.e., positive stimulation facilitates approach, negative stimulation facilitates avoidance), and that it is incapable of extracting the meaning of negations. Consequently, the impulsive system cannot represent nongains or nonlosses in terms of propositions, but only as associations. In particular, a person may experience a situation in which frequent rewards are delivered. For instance, a very talented student may be frequently praised by all teachers. At the same time, some external cues may signal the omission of reward, that is nongain. For instance, the student may learn that she is frequently rewarded, except when she is in math class, because her math teacher does not like her and praises everyone but her. In this situation, the operational principles of the impulsive system predict that the math teacher will become associated with frustration (cf. Higgins, Shah, \& Friedman, 1997) and will serve as a signal of negative stimulation that is, in turn, expected to instigate an avoidance orientation. Analogously, signals of nonpunishment are predicted to become associatively linked to positive affect and thus an approach orientation.

If information about nongains and nonlosses is conveyed verbally, however, a different pattern is predicted to occur. In this case, the valence of the event must be inferred reflectively from negated statements, whereas in the case of conditioning, the valence is already stored in memory. At the same time, because contents of reflective operations are assumed to be retrieved from the impulsive system, the negated concepts will receive activation, thereby instigating a congruent motivational orientation. Take the situation of a student, hearing the sentence "if you do not succeed at the test you'll not get good grades." Within the impulsive system, hearing this sentence is assumed to activate the concepts success and good, as well as not, which are of predominantly positive valence. Thus, perceiving verbal descriptions of potential nongains will instigate an approach orientation. Similarly, perceiving verbal descriptions of potential nonlosses will instigate an avoidance orientation.

In sum, the reflective-impulsive model predicts that information about nongains and nonlosses has opposing effects depending on whether it is conveyed through discriminative stimuli that have acquired their meaning through associative learning or in a verbal format containing negations. Whereas in the former case, nongains are assumed to elicit an avoidance motivation because they cue frustration and hence negative affect, in the latter case an approach orientation is predicted because positive concepts will be activated in memory. Up to now, this prediction has not been tested in an adequate experimental setting. However, some evidence, sampled across experiments and species, can be regarded as first evidence for the viability of this prediction. 
Specifically, in many of the experiments supporting RFT, action-outcome expectations were conveyed verbally, whereas in animal research on operant and Pavlovian conditioning (see Rescorla \& Solomon, 1967), cues for nonreward and nonpunishment acquired their meaning through associative learning. It is significant that human and animal experimentation differs in its results. Studies with human participants match our predictions for the case when information is conveyed verbally. For example, some participants in one experiment by Crowe and Higgins (1997) were instructed that they would not have to perform a disliked task if they do not do poorly on the exercises (prevention focus), while others where instructed that they would have to do a disliked task if they do not do well on the exercises (promotion focus). ${ }^{4}$ In several cognitive tasks, participants in the prevention focus were found to be more cautious and slow, and thus more accurate than participants in a promotion focus (e.g., Förster, Higgins, \& Idson, 1998; Idson, Liberman, \& Higgins, 2000; Shah, Higgins, \& Friedman, 1998). In contrast, results from animal studies match our predictions for associatively learned cues. In one experiment (Ray \& Stein, 1959), rats learned that a high tone was associated with the receiving an electric shock, whereas a low tone was associated with the omission of such a shock. In a second part, the animals had the opportunity to press a bar for the delivery of milk. This type of approach behavior was suppressed if the signal for punishment (the high tone) was presented simultaneously. More interesting, the signal for nonpunishment (low tone) facilitated the approach behavior above baseline responding. Other research reviewed by Rescorla and Solomon (1967) as well as by Klein (1996) indicates that conditioned signals for nonreward facilitate avoidance behavior and that signals for nonpunishment inhibit avoidance behavior.

In sum, the reflective-impulsive model accounts for phenomena of regulatory focus as a joint effect of reflective and impulsive mechanisms. The dissociation of the effects of indirect verbal versus direct conditioned activation of nongain and nonloss expectancies can then be understood as the consequence of different properties of the impulsive system and the reflective system. This interpretation, however, relies on results that were obtained across studies and species. Future research should generate experimental procedures that allow the orthogonal activation of direct versus indirect of expectancies in human participants.

\section{Conclusion}

In this article, we have advanced the position that behavior is determined not only by assessments of probability and value. This means that social behavior

${ }^{4}$ There were other conditions irrelevant to our discussion. is not exclusively determined by people's attitudes. Rather, it is important to consider impulsive influences and study their interaction with the components of reflective determination. This framework integrates concepts from motivational science into a dual-system theory and is able to explain a wide range of phenomena such as habitual versus intentional behavior, spontaneous approach and avoidance behavior, perception-behavior links, and effects of deprivation. Beyond this integrative attempt, the reflective-impulsive model may contribute more than the sum of its parts in that phenomena, that are unexplained assumptions in other models, follow logically from this framework and from its operating characteristics. This includes phenomena as diverse as the processing of negations, the limits of automatic social cognition, or the mechanisms of regulatory focus.

More important, the proposed perspective may help recover some phenomena that are considered to be the precursors of social psychology, specifically, the psychology of mass behavior (Le Bon, 1895; see also Freud, 1921/1922; McDougall, 1920). Despite the insights that have been gained by replacing the mass by the group, social psychologists are ill at ease when it comes to explaining social behaviors that are not guided by people's attitudes, such as panic behaviors, vandalism, riots, uprisings, and many facets of aggression and violence. Unlike Le Bon, we do not have to invoke an irrational and emotional group mind that is susceptible to hypnotic suggestion. Instead, our understanding of the mechanism of impulsive actions and of the conditions under which they occur will provide us with a more complete picture of social behavior.

Another advantage of the reflective-impulsive model is that it lends itself to approaches from neuroscience (see also, Lieberman et al., 2002). Although it seems difficult to link the reflective system and the impulsive system as a whole to specific brain structures, this may well be possible for specific psychological processes described in the model. Take for instance impulsively aggressive behavior that is due to reflective underregulation. Neuroscientists have convincingly argued that such underregulation correlates with structural damage to the prefrontal cortex (Raine, Lencz, Buhrle, LaCasse, \& Colletti, 2000). In addition, damage in the nucleus accumbens may be related to deficits in the impulsive system (Cardinal, Pennicott, Sugathapala, Robbins, \& Everitt, 2001).

The notion that reflectively generated attitudes and impulsive responses that express evaluations might be due to the operation of different systems was recently supported by a neuropsychological study conducted by Phelps and her colleagues (Phelps et al., 2000). Based on findings from brain imaging, it would appear that amygdala activity was correlated with impulsive behavior indicating prejudice against African Americans, while it was not correlated with reflective expressions 
of racial attitudes. This suggests that the amygdala may be capable of detecting stimulus valence extremely fast (Morris, Öhman, \& Dolan, 1998) and before it can be processed by the reflective system. The distinction between flexible and fast acquisition of information in the reflective system and slowly changing representations in the impulsive system was recently linked to neocortical and hippocampal structures (J. L. McClelland et al., 1995). Of course, these few examples are only a sketch of possible interconnections between the two lines of research. A more thorough analysis, however, is beyond the scope of this article.

Another area to which these principles can be extended is that of behavioral disorders. Until 1964, psychological research on social and abnormal phenomena was published in the same scientific journals. Since then, however, normal and abnormal behaviors have been seen as distinct categories and explained by different theoretical models. From the perspective of the reflective-impulsive model, the difference between the two types of behavior is only one of degree, not of kind. What we call "abnormal" can often be described as the chronic determination of a behavior through only one operating system. One example is addiction, a psychological category that may not be confined to the abuse of drugs, but may also describe behaviors that are difficult to control by intention, such as overeating, gambling, watching TV, or surfing the Internet. As another example, phobic behaviors may be understood as being predominantly controlled by the impulsive system. The automatic associations of a stimulus with a fear response (cf. Bouton, Mineka, \& Barlow, 2001) may then be assessed with implicit measures such as the Implicit Association Test (IAT; e.g., Teachman, Gregg, \& Woody, 2001). Similarly, depression may be accompanied by an automatic tendency to negatively evaluate information that is relevant for the self. Results from the IAT suggest that this is the case (Gemar, Segal, Sagrati, \& Kennedy, 2001). Another example of application is panic reactions of crowds. Here, arousal is predicted to diminish reflective processing. At the same time, observing other persons' fearful expressions and flight behavior will fuel own avoidance reactions, particularly fear and flight and further enhance the arousal.

In conclusion, this conceptualization suggests that social psychology should recognize the importance of an impulsive determination of social behavior and study its mechanisms, particularly its interaction with the reflective determinants that are the primary focus of our theorizing. In this endeavor, it may be not enough to duplicate the processes or outcomes of the reflective system and propose implicit decisions. Instead, it seems necessary to study the unique mechanisms that drive the system and understand its adaptive value in guiding behavior under suboptimal circumstances.

As mentioned at the outset, the notion that humans are rational beings is only part of the truth. We know that behavior is not only determined by its anticipated consequences but also driven by forces outside of rational control. However, it is not sufficient to focus on any one of these forces in isolation. To understand what people do, it seems necessary to study the dynamics of behavior as the result of interacting influences. We have proposed that they originate from psychological systems that obey different operational principles. The reflective-impulsive model of social behavior we have suggested is meant to provide a framework for this endeavor. Future research will test its merits.

\section{References}

Aarts, H., \& Dijksterhuis, A. (2000). Habits as knowledge structures: Automaticity in goal-directed behavior. Journal of Personality and Social Psychology, 78, 53-63.

Aarts, H., Dijksterhuis, A., \& De Vries, P. (2001). On the psychology of drinking: Being thirsty and perceptually ready. British Journal of Psychology, 92, 631-642.

Ajzen, I. (1991). The theory of planned behavior. Organizational Behavior and Human Decision Processes, 50, 179-211.

Anderson, J. R. (Ed.). (1981). Cognitive skills and their acquisition. Hillsdale, NJ: Lawrence Erlbaum Associates, Inc.

Anderson, J. R. (1993). Rules of the mind. Hillsdale, NJ: Lawrence Erlbaum Associates, Inc.

Baddeley, A. D. (1986). Working memory. New York: Oxford University Press.

Banaji, M. R. (2001). Implicit attitudes can be measured. In H. L. Roediger III, J. S. Nairne, I. Neath, \& A. Surprenant (Eds.), The nature of remembering: Essays in honor of Robert $G$. Crowder (pp. 117-150). Washington, DC: American Psychological Association.

Bandura, A. (1977). Social learning theory. Englewood Cliffs, NJ: Prentice Hall.

Bargh, J. A. (1990). Auto-motives: Preconscious determinants of social interaction. In E. T. Higgins \& R. M. Sorrentino (Eds.), Handbook of motivation and cognition, Vol. 2 (pp. 93-130). New York: Guilford.

Bargh, J. A. (1996). Automaticity in social psychology. In E. T. Higgins \& A. W. Kruglanski (Eds.), Social psychology: Handbook of basic principles (pp. 169-183). New York: Guilford.

Bargh, J. A. (1997). The automaticity of everyday life. In R. S. Wyer \& T. K. Srull (Eds.), Advances in social cognition: Vol. 10 (pp. 1-61). Hillsdale, NJ: Lawrence Erlbaum Associates, Inc.

Bargh, J. A., \& Barndollar, K. (1996). Automaticity in action: The unconscious as repository of chronic goals and motives. In P. M. Gollwitzer \& J. A. Bargh (Eds.), The psychology of action (pp. 457-481). New York: Guilford.

Bargh, J. A., Chen, M., \& Burrows, L. (1996). Automaticity of social behavior: Direct effects of trait construct and stereotype activation on action. Journal of Personality and Social Psychology, $71,230-244$.

Bargh, J. A., \& Ferguson, M. J. (2000). Beyond behaviorism: On the automaticity of higher mental processes. Psychological Bulletin, 126, 925-945.

Baron, R. S. (2000). Arousal, capacity, and intense indoctrination. Personality and Social Psychology Review, 4, 238-254.

Baumeister, R. F., \& Heatherton, T. F. (1996). Self-regulation failure: An overview. Psychological Inquiry, 7, 1-15.

Bechara, A., Damasio, H., Tranel, D., \& Damasio, A. R. (1997). Deciding advantageously before knowing the advantageous strategy. Science, 275, 1293-1295. 


\section{STRACK AND DEUTSCH}

Bem, D. J. (1967). An alternative interpretation of cognitive dissonance phenomena. Psychological Review, 73, 185-200.

Blair, I. V. (2001). Implicit stereotypes and prejudice. In G. Moskowitz (Ed.), Cognitive social psychology: The Princeton Symposium on the Legacy and Future of Social Cognition (pp. 359-374). Mahwah, NJ: Lawrence Erlbaum Associates, Inc.

Bless, H., \& Forgas, J. P. (Eds.). (2000). The message within: The role of subjective experience in social cognition and behavior. Philadelphia: Psychology Press.

Bodenhausen, G. V. (1993). Emotions, arousal, and stereotypic judgments: A heuristic model of affect and stereotyping. In D. M. Mackie \& D. L. Hamilton (Eds.), Affect, cognition, and stereotyping (pp. 13-37). New York: Academic.

Bodenhausen, G. V., Kramer, G. P., \& Suesser, K. (1994). Happiness and stereotypic thinking in social judgment. Journal of Personality and Social Psychology, 66, 621-632.

Bouton, M. E., Mineka, S., \& Barlow, D. H. (2001). A modern learning theory perspective on the etiology of panic disorder. Psychological Review, 108, 4-32.

Brendl, C. M., Markman, A. B., \& Messner, C. (2003). The devaluation effect: Activating a need devaluates unrelated objects. Journal of Consumer Research, 29, 463-473.

Bruner, J. S. (1957). On perceptual readiness. Psychological Review, 64, 123-152.

Bruner, J. S. (1973). Beyond the information given: Studies in the psychology of knowing. New York: Norton.

Cacioppo, J. T., Priester, J. R., \& Berntson, G. G. (1993). Rudimentary determinants of attitudes: II. Arm flexion and extension have differential effects on attitudes. Journal of Personality and Social Psychology, 65, 5-17.

Cardinal, R. N., Pennicott, D. R, Sugathapala, C. L., Robbins, T. W., \& Everitt, B. J. (2001). Impulsive choice induced in rats by lesions of the nucleus accumbens core. Science, 292, 2499-2501.

Center for the Study of Emotion and Attention. (1995). The international affective picture system: Digitized photographs. Gainesville: University of Florida, Center for Research in Psychophysiology.

Chaiken, S., Liberman, A., \& Eagly, A. H. (1989). Heuristic and systematic processing within and beyond the persuasion context. In J. S. Uleman \& J. A. Bargh (Eds.), Unintended thought (pp. 212-252). New York: Guilford.

Chaiken, S., \& Trope, Y. (Eds.). (1999). Dual-process theories in social psychology. New York: Guilford.

Chen, M., \& Bargh, J. A. (1999). Consequences of automatic evaluation: Immediate behavioral predispositions to approach or avoid the stimulus. Personality and Social Psychology Bulletin, $25,215-224$.

Collins, A. M., \& Quillian, M. R. (1969). Retrieval time from semantic memory. Journal of Verbal Learning and Verbal Behavior, 8 , 240-247.

Crowe, E., \& Higgins, E. T. (1997). Regulatory focus and strategic inclinations: Promotion and prevention in decision making. Organizational Behavior and Human Decision Processes, 69, 117-132.

Darwin, C. R. (1965). The expression of emotions in man and animals. Chicago: University of Chicago Press. (Original work published 1872)

De Houwer, J., Crombez, G., \& Baeyens, F. (2001). On the generality of the affective Simon effect. Cognition and Emotion, 15, 189-206.

Deutsch, R., Gawronski, B., \& Strack, F. (2003). "Not good" may feel quite positive. Affective and behavioral consequences of processing negated information. Unpublished manuscript, University of Würzburg.

Deutsch, R., \& Strack, F. (2002). Evaluative learning with delayed gratification. Impulsive and reflective processes. Unpublished manuscript, University of Würzburg.
Devine, P. G. (1989). Stereotypes and prejudice: Their automatic and controlled components. Journal of Personality and Social Psychology, 56, 5-18.

Dickinson, A., \& Balleine, B. W. (2002). The role of learning in the operation of motivation systems. In H. Pashler \& C. R. Gallistel (Eds.), Steven's handbook of experiemental psychology: Vol. 3. Learning, motivation, and emotion (3rd ed., pp. 497-533). New York: John Wiley \& Sons.

Dijksterhuis, A., \& Bargh, J. A. (2001). The perception-behavior expressway: Automatic effects of social perception on social behavior. In M. P. Zanna (Ed.), Advances in experimental social psychology, Vol. 33 (pp. 1-40). San Diego: Academic.

Dijksterhuis, A., Bargh, J. A., \& Miedema, J. (2000). Of men and mackerels: Attention, subjective experience, and automatic social behavior. In H. Bless \& J. P. Forgas (Eds.), The message within: The role of subjective experience in social cognition and behavior (pp. 37-51). Philadelphia: Psychology Press.

Dovidio, J. F., Kawakami, K., Johnson, C., Johnson, B., \& Howard, A. (1997). On the nature of prejudice: Automatic and controlled processes. Journal of Experimental Social Psychology: Special Issue on Unconscious Processes in Stereotyping and Prejudice, $33,510-540$.

Drobes, D. J., Miller, E. J., Hillman, C. H., Bradley, M. M., Cuthbert, B. N., \& Lang, P. J. (2001). Food deprivation and emotional reactions to food cues: Implications for eating disorders. Biological Psychology, 57, 153-177.

Eagly, A. H., \& Chaiken, S. (1993). The psychology of attitudes. San Diego: Harcourt.

Epstein, S. (1991). Cognitive-experiential self-theory: An integrative theory of personality. In R. Curtis (Ed.), The relational self: Theoretical conergences in psychoanalytical, social, and personality psychology (pp. 111-137). New York: Guildford.

Erber, R. (1991). Affective and semantic priming: Effects of mood on category accessibility. Journal of Experimental Social Psychology, 27, 480-498.

Farnham, S. D., Greenwald, A. G., \& Banaji, M. R. (1999). Implicit self-esteem. In D. Abrams \& M. A. Hogg (Eds.), Social identity and social cognition (pp. 230-248). Malden, MA: Blackwell.

Fazio, R. H. (1986). How do attitudes guide behavior? In R. M. Sorrentino \& E. T. Higgins (Eds.), Handbook of motivation and cognition: Foundations of social behavior (pp. 204-243). New York: Guilford.

Fazio, R. H. (1990). Multiple processes by which attitudes guide behavior: The MODE model as an integrative framework. In M. P. Zanna (Ed.), Advances in experimental social psychology, Vol. 23 (pp. 75-109). San Diego: Academic.

Fazio, R. H. (2001). On the automatic activation of associated evaluations: An overview. Cognition and Emotion, 15, 115-141.

Fazio, R. H., \& Olson, M. A. (2003). Implicit measures in social cognition research: Their meaning and use. Annual Review of Psychology, 54, 297-327.

Fazio, R. H., Sanbonmatsu, D. M., Powell, M. C., \& Kardes, F. R. (1986). On the automatic activation of attitudes. Journal of Personality and Social Psychology, 50, 229-238.

Fielder, K., Armbruster, T., Nickel, S. Walther, E., \& Asbeck, J. (1996). Constructive memory \& social judgement: Experiments in the self-verification of question contents. Journal of Personality and Social Psychology, 71, 861-873.

Förster, J., Higgins, E. T., \& Idson, L.C. (1998). Approach and avoidance strength during goal attainment: Regulatory focus and the "goal looms larger" effect. Journal of Personality and Social Psychology, 75, 1115-1131.

Förster, J., \& Strack, F. (1996). The influence of overt head movements on memory for valenced words: A case of conceptual-motor compatibility. Journal of Personality and Social Psychology, 71, 421-430. 
Förster, J., \& Strack, F. (1997). Motor actions in retrieval of valenced information: A motor congruence effect. Perceptual and Motor Skills, 85, 1419-1427.

Förster, J., \& Strack, F. (1998). Motor actions in retrieval of valenced information: II. Boundary conditions for motor congruence effects. Perceptual and Motor Skills, 86, 1423-1426.

Freud, S. (1922). Group psychology and the analysis of the ego. New York: Liverright. (Original work published 1921)

Freud, S. (1949). New introductory lectures on psychoanalysis. London: Hogarth. (Original work published 1933)

Friedman, M. (1976). Price theory. Chicago: Aldine.

Gawronski, B., \& Strack, F. (in press). On the propositional nature of cognitive consistency: Dissonance changes explicit, but not implicit attitudes. Journal of Experimental Social Psychology.

Gemar, M. C., Segal, Z. V., Sagrati, S., \& Kennedy, S. J. (2001). Mood-induced changes on the Implicit Association Test in recovered depressed patients. Journal of Abnormal Psychology, $110,282-289$.

Gilbert, D. T. (1989). Thinking lightly about others: Automatic components of the social inference process. In J. S. Uleman \& J. A. Bargh (Eds.), Unintended thought (pp. 189-211). New York: Guilford.

Gilbert, D. T. (1991). How mental systems believe. American Psychologist, 46, 107-119.

Gilbert, D. T., Krull, D. S., \& Malone, P. S. (1990). Unbelieving the unbelievable: Some problems in the rejection of false information. Journal of Personality and Social Psychology, 59, 601-613.

Gilbert, D. T., Tafarodi, R. W., \& Malone, P. S. (1993). You can't not believe everything you read. Journal of Personality and Social Psychology, 65, 221-233.

Gilovich, T., \& Griffin, D. (2002). Introduction-Heuristics and biases: Then and now. In T. Gilovich, D. Griffin, \& D. Kahneman (Eds.), Heuristic and biases: The psychology of intuitive judgment (pp. 1-18). New York: Cambridge University Press.

Gollwitzer, P. M. (1999). Implementation intentions. Strong effects of simple plans. American Psychologist, 54, 493-503.

Gray, J. A. (1982). The neuropsychology of anxiety: An enquiry into the functions of the septo-hippocampal system. New York: Clarendon Press/Oxford University Press.

Greene, J. D., Sommerville, R. B., Nystrom, L. E., Darley, J. M., \& Cohen J. D. (2001). An fMRI investigation of emotional engagement in moral judgment. Science, 293, 2105-2108.

Greenwald, A. G., \& Banaji, M. R. (1995). Implicit social cognition: Attitudes, self-esteem, and stereotypes. Psychological Review, 102, 4-27.

Greenwald, A. G., Banaji, M. R., Rudman, L. A., Farnham, S. D., Nosek, B. A., \& Mellott, D. S. (2002). A unified theory of implicit attitudes, stereotypes, self-esteem, and self-concept. Psychological Review, 109, 3-25.

Greenwald, A. G., McGhee, D. E., \& Schwartz, J. L. K. (1998). Measuring individual differences in implicit cognition: The Implicit Association Test. Journal of Personality and Social Psychology, 74, 1464-1480.

Gregory, W. L., Cialdini, R. B., \& Carpenter, K. M. (1982). Self-relevant scenarios as mediators of likelihood estimates and compliance: Does imagining make it so? Journal of Personality and Social Psychology, 43, 89-99.

Haidt, J. (2001). The emotional dog and its rational tail: A social intuitionist approach to moral judgment. Psychological Review, 108, 814-834.

Helmholtz, H. (1867). Handbuch der physiologischen Optik [Handbook of physiological optics]. Leipzig, Germany: Voss.

Higgins, E. T. (1996). Knowledge activation: Accessibility, applicability, and salience. In E. T. Higgins \& A. W. Kruglanski (Eds.), Social psychology: Handbook of basic principles (pp. 133-168). New York: Guilford.

Higgins, E. T. (1997). Beyond pleasure and pain. American Psychologist, 52, 1280-1300.
Higgins, E. T., \& Kruglanski, A. W. (Eds.). (2000). Motivational science. Philadelphia: Psychology Press.

Higgins, E. T., Rholes, W. S., \& Jones, C. R. (1977). Category accessibility and impression formation. Journal of Experimental Social Psychology, 13, 141-154.

Higgins, E. T., Shah, J. Y., \& Friedman, R. (1997). Emotional responses to goal attainment: Strength of regulatory focus as moderator. Journal of Personality and Social Psychology, 72, 515-525.

Horn, L. R. (1989). A natural history of negation. Chicago: University of Chicago Press.

Hull, C. L. (1943). Principles of behavior. New York: Appleton-Century-Crofts.

Hummel, J. E., \& Holyoak, K. J. (2003). A symbolic-connectionist theory of relational inference and generalization. Psychological Review, 110, 220-264.

Idson, L. C., Liberman, N., \& Higgins, E. T. (2000). Distinguishing gains from nonlosses and losses from nongains: A regulatory focus perspective on hedonic intensity. Journal of Experimental Social Psychology, 36, 252-274.

Jacoby, L. L., Kelley, C., Brown, J., \& Jasechko, J. (1989). Becoming famous overnight: Limits on the ability to avoid unconscious influences of the past. Journal of Personality and Social Psychology, 56, 326-338.

James, W. (1890). The principles of psychology. New York: Holt.

Johnson, M. K., \& Hirst, W. (1991). MEM: Memory subsystems as processes. In A. Collins, S. Gathercole, M. Conway, \& P. Morris (Eds.), Theories of memory (pp. 241-286). Hillsdale, NJ: Lawrence Erlbaum Associates, Inc.

Kahneman, D. (1999). Objective happiness. In D. Kahneman, E. Diener, \& N. Schwarz (Eds.), Well-being: The foundations of hedonic psychology (pp. 3-25). New York: Russell Sage Foundation.

Kahneman, D., \& Frederick, S. (2002). Representativeness revisited: Attribute substitution in intuitive judgment. In T. Gilovich, D. Griffin, \& D. Kahneman (Eds.), Heuristic and biases: The psychology of intuitive judgment (pp. 49-81). New York: Cambridge University Press.

Kelley, H. H. (1967). Attribution theory in social psychology. In D. Levine (Ed.), Nebraska Symposium on Motivation, Vol. 15 (pp. 192-241). Lincoln: University of Nebraska Press.

Keltner, D., Gruenfeld, D. H., \& Anderson, C. (2003). Power, approach, and inhibition. Psychological Review, 110, 265-284.

Klein, S. B. (1996). Learning. Principles and applications (3rd ed.). New York: McGraw-Hill.

Koriat, A. (1993). How do we know what we know? The accessibility model of the feeling of knowing. Psychological Review, 100, 609-639.

Krauss, R. M., Chen, Y., \& Gottesman, R. F. (2000). Lexical gestures and lexical access: A process model. In D. McNeill (Ed.), Language and gesture: Window into thought and action (pp. 261-283). New York: Cambridge University Press.

Kruglanski, A. W., \& Thompson, E. P. (1999). Persuasion by a single route: A view from the unimodel. Psychological Inquiry, 10, 83-109.

Kuhl, J., \& Goschke, T. (1994). A theory of action control: Mental subsystems, modes of control, and volitional conflict-resolution strategies. In J. Kuhl \& J. Beckman (Eds.), Volition and personality: Action versus state orientation (pp. 93-124). Seattle, WA: Hogrefe \& Huber.

Laird, J. D. (1974). Self-attribution of emotion: The effects of expressive behavior on the quality of emotional experience. Journal of Personality and Social Psychology, 29, 475-486.

Lambert, A. J., Payne, B. K., Jacoby, L. L., Shaffer, L. M., Chasteen, A. L., \& Khan, S. K. (2003). Stereotypes as dominant responses: On the "social facilitation" of prejudice in anticipated public contexts. Journal of Personality and Social Psychology, 84, 277-295.

Lang, P. J. (1995). The emotion probe-Studies of motivation and attention. American Psychologist, 50, 372-385. 


\section{STRACK AND DEUTSCH}

Lang, P. J., Bradley, M. M., \& Cuthbert, B. N. (1990). Emotion, attention, and the startle reflex. Psychological Review, 97,377-395.

Langer, E. J., Blank, A., \& Chanowitz, B. (1978). The mindlessness of ostensibly thoughtful action: The role of "placebic" information in interpersonal interaction. Journal of Personality and Social Psychology, 36, 635-642.

Lavy, E. H., \& van den Hout, M. A. (1993). Attentional bias for appetitive cues: Effects of fasting in normal subjects. Behavioural and Cognitive Psychotherapy, 21, 297-310.

Lazarus, R. S. (1984). On the primacy of cognition. American Psychologist, 39, 124-129.

Le Bon, G. (1895). Psychologie des foules [Psychology of the crowd]. Paris: Alcan.

LeDoux, J. E. (1995). Emotion: Clues from the brain. Annual Review of Psychology, 46, 209-235.

Lewin, K. (1935). A dynamic theory of personality. New York: McGraw-Hill.

Libet, B., Gleason, C. A., Wright, E. W., \& Pearl, D. K. (1983). Time of conscious intention to act in relation to onset of cerebral activity (readiness-potential): The unconscious initiation of a freely voluntary act. Brain, 106, 623-642.

Lieberman, M. D., Gaunt, R., Gilbert, D. T., \& Trope, Y. (2002). Reflection and reflexion: A social cognitive neuroscience approach to attributional inference. In M. P. Zanna (Ed.), Advances in experimental social psychology, Vol. 34 (pp. 199-249). New York: Academic.

Logan, G. D. (1988). Toward an instance theory of automatization. Psychological Review, 95, 492-527.

Logan, G. D., Schachar, R. J., \& Tannock, R. (1997). Impulsivity and inhibitory control. Psychological Science, 8, 60-64.

Lotze, H. (1852). Medicinische Psychologie oder Physiologie der Seele [Medical psychology or the physiology of the soul]. Leipzig, Germany: Weidmann'sche Buchhandlung.

Maass, A., Castelli, L., \& Arcuri, L. (2000). Measuring prejudice: Implicit versus explicit techniques. In D. Capozza \& R. Brown (Eds.), Social identity processes: Trends in theory and research (pp. 96-116). London: Sage.

MacDonald, M. C., \& Just, M. A. (1989). Changes in activation levels with negation. Journal of Experimental Psychology: Learning, Memory, and Cognition, 15, 633-642.

McDougall, W. (1920). The group-mind. A sketch of the principles of collective psychology. Oxford, UK: Putnam.

Mall, R. A. (1975). On reflection and negation. Philosophy and Phenomenological Research, 35, 79-92.

Marr, D. (1982). Vision. A computational investigation into the human representation and processing of visual information. San Francisco: Freeman.

Martin, L. L., Harlow, T. F., \& Strack, F. (1992). The role of bodily sensations in the evaluation of social events. Personality and Social Psychology Bulletin, 1, 412-419.

Martin, L. L., Seta, J. J., \& Crelia, R. A. (1990). Assimilation and contrast as a function of people's willingness and ability to expend effort in forming an impression. Journal of Personality and Social Psychology, 59, 27-37.

McClelland, D. C., \& Atkinson, J. W. (1948). The projective expression of needs: I. The effect of different intensities of the hunger drive on perception. Journal of Psychology, 25, 205-222.

McClelland, J. L., McNaughton, B. L., \& O'Reilly, R. C. (1995). Why there are complementary learning systems in the hippocampus and neocortex: Insights from the successes and failures of connectionist models of learning and memory. Psychological Review, 102, 419-457.

Metcalfe, J., \& Mischel, W. (1999). A hot/cool-system analysis of delay of gratification: Dynamics of willpower. Psychological Review, 106, 3-19.

Mele, A. R. (1992). Irrationality: An essay on akrasia, self-deception, and self-control. New York: Oxford University Press.
Morris, J. S., Öhman, A., \& Dolan, R. J. (1998). Conscious and unconscious emotional learning in the human amygdala. Nature, 393, 467-470.

Mussweiler, T., \& Strack, F. (1999). Comparing is believing: A selective accessibility model of judgmental anchoring. In W. Stroebe \& M. Hewstone (Eds.), European review of social psychology, Vol. 10 (pp. 135-167). Chichester, England: Wiley.

Neumann, R., Förster, J., \& Strack, F. (2003). Motor compatibility: The bidirectional link between behavior and evaluation. In J. Musch \& K. C. Klauer (Eds.), The psychology of evaluation. Affective processes in cognition and emotion (pp. 371-391). Mahwah, NJ: Lawrence Erlbaum Associates, Inc.

Neumann, R., \& Hess, M. (2001). The latency of facial action differentiates the valence of processed information: Evidence that facial action is activated by evaluative processing. Unpublished manuscript, University of Würzburg.

Neumann, R., Seibt, B., \& Strack, F. (2001). The influence of mood on the intensity of emotional responses: Disentangling feeling and knowing. Cognition and Emotion, 15, 725-747.

Neumann, R., \& Strack, F. (2000). Approach and avoidance: The influence of proprioceptive and exteroceptive cues on encoding of affective information. Journal of Personality and Social Psychology, 79, 39-48.

Norman, D. A., \& Shallice, T. (1986). Attention to action. Willed and automatic control of behavior. In R. J. Davidson, G. E. Schwartz, \& D. Shapiro (Eds.), Consciousness and self regulation: Advances in research (pp. 1-18). New York: Plenum.

Ouellette, J. A., \& Wood, W. (1998). Habit and intention in everyday life: The multiple process by which past behavior predicts future behavior. Psychological Bulletin, 124, 54-74.

Paulhus, D. L., \& Lim, D. T. K. (1994). Arousal and evaluative extremity in social judgments: A dynamic complexity model. European Journal of Social Psychology, 24, 89-99.

Palmeri, T. J. (1997). Exemplar similarity and the development of automaticity. Journal of Experimental Psychology: Learning, Memory, and Cognition, 23, 324-354.

Petty, R. E., \& Cacioppo, J. T. (1986). The elaboration likelihood model of persuasion. In L. Berkowitz (Ed.), Advances in experimental social psychology, Vol. 19 (pp. 123-205). New York: Academic.

Phelps, E. A., O’Connor, K. J., Cunningham, W. A., Funayama, S., Gatenby, J. C., Gore, J. C., et al. (2000). Performance on indirect measures of race evaluation predicts amygdala activation. Journal of Cognitive Neuroscience, 12, 729-738.

Raine, A., Lencz, T., Buhrle, S., LaCasse, L., \& Colletti, P. (2000). Reduced prefrontal gray matter volume and reduced autonomic activity in antisocial personality disorder. Archives of General Psychiatry, 57, 119-127.

Ray, O. S., \& Stein, L. (1959). Generalization of conditioned suppression. Journal of the Experimental Analysis of Behavior, 2, 357-361.

Rescorla, R. A., \& Solomon, R. L. (1967). Two-process learning theory. Psychological Review, 73, 151-182.

Riskind, J. H. (1984). They stoop to conquer: Guiding and self-regulatory functions of physical posture after success and failure. Journal of Personality and Social Psychology, 47, 479-493.

Ross, L., Lepper, M., \& Hubbard, M. (1975). Perseverence in self-perception and social perception: Biased attributional processes in the debriefing paradigm. Journal of Personality and Social Psychology, 32, 880-892.

Russell, J. A. (2003). Core affect and the psychological construction of emotion. Psychological Review, 110, 145-172.

Schreiber, C. A., \& Kahneman, D. (2000). Determinants of the remembered utility of aversive sounds. Journal of Experimental Psychology: General, 129, 27-42.

Schwarz, N., \& Bohner, G. (2001). The construction of attitudes. In A. Tesser \& N. Schwarz (Eds.), Blackwell handbook of social psychology: Vol. 1, Intraindividual processes (pp. 436-457). Oxford, England: Blackwell. 
Schwarz, N., \& Clore, G. L. (1983). Mood, misattribution, and judgments of well-being: Informative and directive functions of affective states. Journal of Personality and Social Psychology, 45, 513-523.

Schwarz, N., \& Clore, G. L. (1996). Feelings and phenomenal experiences. In E. T. Higgins \& A. W. Kruglanski (Eds.), Social psychology: Handbook of basic principles (pp. 433-465). New York: Guilford.

Seibt, B., Häfner, M., \& Deutsch, R. (2003). Prepared to eat: How immediate affective and motivational responses to food cues are influenced by food deprivation. Unpublished manuscript, University of Würzburg.

Seibt, B., \& Neumann, R. (2002). The influence of unspecific motor-programs on experiencing emotions. Unpublished manuscript, University of Würzburg.

Shah, J., Higgins, E. T., \& Friedman, R.S. (1998). Performance incentives and means: How regulatory focus influences goal attainment. Journal of Personality and Social Psychology, 74, 285-293.

Sloman, S. A. (1996). The empirical case for two systems of reasoning. Psychological Bulletin, 119, 3-22.

Smith, E. R. (1994). Procedural knowledge and processing strategies in social cognition. In R. S. Wyer \& T. K. Srull (Eds.), Handbook of social cognition (pp. 99-152). Hillsdale NJ: Lawrence Erlbaum Associates, Inc.

Smith, E. R. (1998). Mental representation and memory. In D. T. Gilbert, S. T. Fiske, \& G. Lindzey (Eds.), Handbook of social psychology, Vol. 1 (4th ed., pp. 391-445). New York: Oxford University Press.

Smith, E. R., Branscombe, N. R., \& Borman, C. (1988). Generality of the effects of practice on social judgment tasks. Journal of Personality and Social Psychology, 54, 385-395.

Smith, E. R., \& DeCoster, J. (2000). Dual process models in social and cognitive psychology: Conceptual integration and links to underlying memory systems. Personality and Social Psychology Review, 4, 108-131.

Smith, E. R., \& Neumann, R. (in press). Emotion considered from the perspective of dual-process models. In L. Feldman Barrett, P. Niedenthal, \& P. Winkielman (Eds.), Emotion: Conscious and unconscious. New York: Guilford.

Solarz, A. K. (1960). Latency of instrumental responses as a function of compatibility with the meaning of eliciting verbal signs. Journal of Experimental Psychology, 59, 239-245.

Stepper, S., \& Strack, F. (1993). Proprioceptive determinants of emotional and nonemotional feelings. Journal of Personality and Social Psychology, 64, 211-220.

Strack, F. (1992). The different routes to social judgments: Experiential versus informational strategies. In L. L. Martin \& A. Tesser, (Eds.), The construction of social judgments (pp. 249-275). Hillsdale, NJ: Lawrence Erlbaum Associates, Inc.

Strack, F. (1999). Beyond dual-process models: Toward a flexible regulation system. Psychological Inquiry, 10, 166-169.

Strack, F., \& Hannover, B. (1996). Awareness of influence as a precondition for implementing correctional goals. In P. Gollwitzer \& J. A. Bargh (Eds.), The psychology of action: Linking cognition and motivation to behavior (pp. 579-595). New York: Guilford.

Strack, F., Martin, L. L., \& Stepper, S. (1988). Inhibiting and facilitating conditions of the human smile: A nonobtrusive test of the facial feedback hypothesis. Journal of Personality and Social Psychology, 54, 768-777.

Strack, F., \& Mussweiler, T. (1997). Explaining the enigmatic anchoring effect: Mechanisms of selective accessibility. Journal of Personality and Social Psychology, 73, 437-446.

Strack, F., \& Neumann, R. (1996). "The spirit is willing, but the flesh is weak": Beyond mind-body interactions in human decision-making. Organizational Behavior and Human Decision Processes, 65, 300-304.
Strack, F., \& Neumann, R. (2000). Furrowing the brow may undermine perceived fame: The role of facial feedback in judgments of celebrity. Personality and Social Psychology Bulletin, 26, 762-768.

Sutton, S. K., \& Davidson, R. J. (1997). Prefrontal brain asymmetry: A biological substrate of the behavioral approach and inhibition systems. Psychological Science, 8, 204-210.

Teachman, B. A., Gregg, A. P., \& Woody, S. R. (2001). Implicit associations for fear-relevant stimuli among individuals with snake and spider fears. Journal of Abnormal Psychology, 110, 226-235.

Thorndike, E. L. (1911). Animal intelligence. New York: Macmillan.

Trope, Y. (1986). Identification and inferential processes in dispositional attribution. Psychological Review, 93, 239-257.

Tulving, E. (1985). Memory and consciousness. Canadian Psycholgy, 26, 1-12.

Tversky, A., \& Kahneman, D. (1973). Availability: A heuristic for judging frequency and probability. Cognitive Psychology, 42, 207-232.

Tversky, A., \& Kahneman, D. (1974). Judgment under uncertainty: Heuristics and biases. Science, 185, 1124-1131.

Tversky, A., \& Kahneman, D. (1982). Judgments of and by representativeness. In D. Kahneman, P. Slovic, \& A. Tversky (Eds.), Judgment under uncertainty: Heuristics and biases (pp. 84-98). New York: Cambridge University Press.

Uleman, J. S. (1999). Spontaneous versus intentional inferences in impression formation. In S. Chaiken \& Y. Trope (Eds.), Dual-process theories in social psychology (pp. 141-160). New York: Guilford.

Wason, P. C. (1959). The processing of positive and negative information. Quarterly Journal of Experimental Psychology, 11, 92-107

Wason, P. C., \& Jones, S. (1963). Negatives: Denotation and connotation. British Journal of Psychology, 54, 299-307.

Wänke, M., Bohner, G., \& Jurkowitsch, A. (1997). There are many reasons to drive a BMW: Does imagined ease of argument generation influence attitudes? Journal of Consumer Research, 24, 170-177.

Wegner, D. M. (2002). The illusion of conscious will. Cambridge, MA: MIT Press.

Wegner, D. M., Ansfield, M., \& Pilloff, D. (1998). The putt and the pendulum: Ironic effects of the mental control of action. Psychological Science, 9, 196-199.

Wegner, D. M., Coulton, G. F., \& Wenzlaff, R. (1985). The transparency of denial: Briefing in the debriefing program. Journal of Personality and Social Psychology, 49, 338-346.

Wells, G. L., \& Petty, R. E. (1980). The effects of overt head movements on persuasion: Compatibility and incompatibility of responses. Basic and Applied Social Psychology, 1, 219-230.

Wilson, T. D., Lindsey, S., \& Schooler, T. Y. (2000). A model of dual attitudes. Psychological Review, 107, 101-126.

Winkielman, P., \& Cacioppo, J. T. (2001). Mind at ease puts a smile on the face: Psychophysiological evidence that processing facilitation increases positive affect. Journal of Personality and Social Psychology, 81, 989-1000.

Wispe, L. G., \& Drambarean, N. C. (1953). Physiological need, word frequency, and visual duration thresholds. Journal of Experimental Psychology, 46, 25-31.

Yerkes, R. M, \& Dodson, J. D. (1908). The relation of strength of stimulus to rapidity of habit formation. Journal of Comparative and Neurological Psychology, 18, 459-482.

Zajonc, R. B. (1965). Social facilitation. Science, 149, 269-274.

Zajonc, R. B. (1980). Feeling and thinking: Preferences need no inferences. American Psychologist, 35, 151-175.

Zajonc, R. B., Murphy, S. T., \& Inglehart, M. (1989). Feeling and facial efference: Implications of the vascular theory of emotion. Psychological Review, 96, 395-416. 